Document downloaded from:

http://hdl.handle.net/10251/169180

This paper must be cited as:

Torregrosa, AJ.; Martín, J.; Novella Rosa, R.; Thein, K. (2020). Estimation of the in-cylinder residual mass fraction at Intake Valve Closing in a 2-stroke High-Speed Direct-Injection Compression-Ignition engine. International Journal of Engine Research. 21(5):838-855. https://doi.org/10.1177/1468087418813406

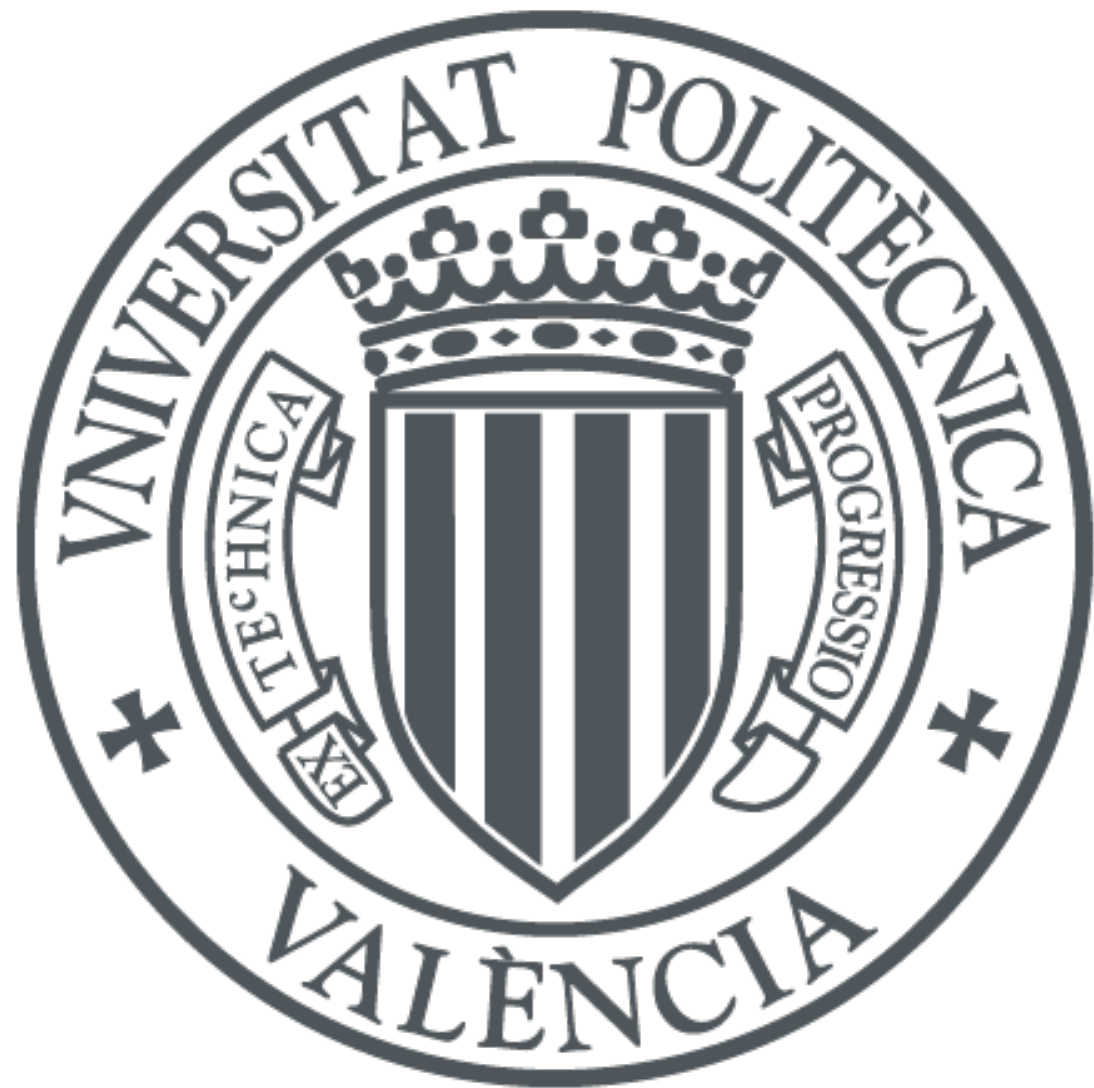

The final publication is available at

https://doi.org/10.1177/1468087418813406

Copyright SAGE Publications

Additional Information

This is the author's version of a work that was accepted for publication in International Journal of Engine Research. Changes resulting from the publishing process, such as peer review, editing, corrections, structural formatting, and other quality control mechanisms may not be reflected in this document. Changes may have been made to this work since it was submitted for publication. A definitive version was subsequently published as https://doi.org/10.1177/1468087418813406. 


\title{
Estimation of the in-cylinder residual \\ mass fraction at Intake Valve Closing in \\ a 2-stroke High-Speed Direct-Injection \\ Compression-Ignition engine
}

\author{
A. Torregrosa, J. Martín, R. Novella, K. Thein
}

\begin{abstract}
New combustion concepts and engine designs are being currently investigated in order to comply with upcoming pollutant regulations and reduce fuel consumption. In this context, 2-stroke architectures appear as a promising solution for the implementation of some combustion concepts. However, scavenging processes in a 2-stroke engine are much more challenging than for a 4-stroke engine, and the residual mass of burnt gases retained inside the cylinder needs to be properly determined in order to keep control over the in-cylinder composition, hence over the combustion conditions and pollutant emissions.

In the present study, a new methodology for the estimation of the Internal Residual Gas fraction (IGR) is introduced, which is based on the thermodynamic processes occurring in the engine investigated and makes use of basic engine instrumentation and measurement equipment usually available in a conventional test cell. Several versions of the estimator were developed so that different requirements could be met, such as those of real-time estimation on an engine test bench but with reduced precision or, on the contrary, highly precise but time-consuming computations for post-processing purposes and combustion diagnosis. The consistency of the IGR estimator was then validated through its application to real engine tests at different operating points.
\end{abstract}

\section{Keywords}

Engine testing, Combustion diagnostics, 2-stroke engine, Residual gas fraction, Engine thermodynamics

\section{Introduction}

In the last years, reciprocating engines have evolved thanks to an increasing knowledge of the mechanisms controlling the scavenging and the injection-combustion processes. The availability of both improved experimental techniques and of better predictive and diagnosis models has been the key to allow to tackle, from different points of view, the study of the involved phenomena.

The processes taking place in the engine are diverse and often complex; it is thus usual to address their description with different models in order to optimize the precision and the calculation resources: highly accurate models are used to perform the main calculations whereas less precise models provide boundary and initial conditions. Therefore, models focused on the scavenging processes usually include a combustion sub-model to provide information allowing a proper setting of boundary conditions related with the thermodynamical and/or chemical phenomena occurring inside the cylinder [1, 2, 3]. Alternatively, different models aimed at calculating in-cylinder processes, such as predictive zero-dimensional [4], quasi-dimensional or phenomenological $[5,6,7,8]$, multidimensional $[9,10]$ or combustion analysis models $[11,12]$ require predefined initial conditions, usually at Intake Valve Closing (IVC).

The importance of the thermodynamic conditions (pressure and temperature) and the composition at IVC is variable depending on the modeling approach. As highlighted in several research works, in the case of predictive models, a small uncertainty in the temperature at IVC may affect the combustion delay [13], the combustion velocity [14, 15] or pollutant formation [16, 17]. Similarly, the amount of

CMT-Motores Térmicos, Universitat Politècnica de València, Camino de Vera s/n, 46022, Valencia, Spain

\section{Corresponding author:}

Jaime Martín, CMT-Motores Térmicos, Universitat Politècnica de València, Camino de Vera s/n, 46022, Valencia, Spain

Email: jaimardi@mot.upv.es 
residual mass and its composition affect the combustion delay in Compression Ignition (CI) engines [18]. For the combustion analysis from in-cylinder pressure, uncertainties in the conditions at IVC were not usually as critical as in predictive models, because the key input is the experimental measured pressure which is substantially independent from any other conditions at IVC. However, the errors in the temperature evolution and the heat release law due to uncertainties in the initial conditions are not negligible [19]. Such errors are justified considering the conventional procedure used to determine conditions at IVC in combustion analysis:

1. Firstly, the absolute level of in-cylinder pressure must be set, which can be done using either an experimental reference pressure or a thermodynamic method. In the first case, referencing through the intake or exhaust manifold pressures during the scavenging period [20,21, 22] or though instantaneous measurements with a piezo-resistive transducer at the bottom of the liner [23] are the most common methods. Thermodynamic methods are based on the assumption of a polytropic evolution of the gases or on the minimization of the rate of heat release (RoHR) during the compression, until the combustion starts [24, 25], or throughout the compression and expansion phases in the case of motored engine tests [21, 11].

2. Once the in-cylinder pressure is properly referenced, the trapped mass at IVC can be estimated as in (Eq. 1):

$$
m_{I V C}=m_{t o t}^{i n t}+m_{r e s}-m_{s c}
$$

where $m_{\text {tot }}^{\text {int }}$ is the total intake mass (fresh air and EGR), $m_{r e s}$ is the residual mass from the previous cycle and $m_{s c}$ is the short-circuited mass. Both $m_{r e s}$ and $m_{s c}$ depend on the characteristic fluid-dynamic behaviour of the engine during the scavenging period, which is highly dependent on the operating conditions, on the manifold characteristics and, most notably, on valve timing. Short-circuited mass is usually small in 4-stroke engines, where the intake and exhaust processes have dedicated strokes. The main contribution to the mass at IVC therefore is, apart from the intake mass (which can be measured), the residual mass. In the case of 4-stroke CI engines, the residual mass is generally below $10 \%$, usually about $5 \%$, and cannot exceed $20 \%$ in 4-stroke Spark-Ignition (SI) engines [26, 27]. On the contrary, in the case of 2-stroke engines the scavenging process is much shorter than in 4-stroke engines and the overlap of the intake and exhaust periods (which represents about
$20 \%$ of the engine cycle for the engine used in the present study) can lead to high levels of both residual and short-circuited masses: depending on valve timing and intake/exhaust conditions, more than $50 \%$ of the mass at IVC can be residuals, and more than $35 \%$ of the intake mass can be short-circuited in the case of conventional 2-stroke engines [28, 29], and these parameters have also proved to be critical in the case of free-piston engines [30, 31] thus generalizing the importance of internal and boundary flow patterns on 2-stroke in-cylinder conditions. Moreover, a tradeoff between trapping ratio and scavenging efficiency is often observed. In any case, the experimental determination of $m_{r e s}$ and $m_{s c}$, even though it might be possible in some cases, is very rarely performed (unlike $m_{\text {tot }}^{\text {int }}$ ) and they are usually obtained from theoretical estimations.

3. When the pressure and mass at IVC are determined, the temperature is calculated by means of a state equation. Normally the perfect gas assumption is used [1, 11, 32, 33]; however, more complex proposals can be found in the literature [34].

If the temperature is calculated following the above procedure, the heat release will be affected by the uncertainty in the mass at IVC, in different ways. On the one hand, if the heat rejection to the chamber walls is not considered (net heat release $[1,13,16,25])$, only the work on the piston and the variation of the sensible internal energy of the gas are accounted for in the First Law of Thermodynamics. In this case, the most important parameter for the calculation is the adiabatic exponent, which depends on the temperature and the composition $[11,35]$, both of which are directly affected by uncertainties in $m_{r e s}$ and $m_{s c}$. On the other hand, if some heat transfer model is considered, the chemical energy released by the fuel during combustion can be obtained (gross heat release $[1,11,36,37,38]$ ). In this case, there is an additional effect of the temperature uncertainty due to the heat transfer to the walls. Moreover, the uncertainty in temperature due to the incorrect estimates of mass and composition at IVC can affect the pressure referencing if a thermodynamic method is used.

Different authors have reported the effect of errors in the temperature [37] or in the trapped mass [36, 39, 40] on the heat release law, mainly produced by the change of the specific heat of the charge and, to a lower extent, by heat transfer to the walls. According to Brunt et al. [37] and Payri et al. [39] an error of $10 \%$ in the temperature or the mass of the charge will lead to a $3 \%$ error in the cumulated heat 
release. Also, the in-cylinder temperature is a determining parameter for auto-ignition (especially in Diesel engines) and a misevaluation can lead to either unexpected knocking conditions or misfire and difficult cold-start [41]. Therefore, errors in the trapped mass lower than 4-5\% must be pursuit for combustion analysis purposes.

In order to estimate the mass and composition at IVC, different theoretical and experimental approaches can be used. An experimental value of $m_{s c}$ can be obtained by adding a certain amount of fuel to the intake flow and then determining the Trapping Ratio (TR) by measuring the fuel molar fraction at the exhaust $[42,43]$ : if a complete combustion of the trapped tracer fuel is guaranteed, a reliable estimation of the short-circuited mass can be obtained. Even though this method is not usually applied (due to the additional setup requirements), it is the procedure used here to obtain $m_{s c}$ in a 2-stroke Diesel engine. Although the TR can be experimentally measured, obtaining the residual mass from experiments is far more complex and expensive [44, 45]. A suitable estimate of $m_{\text {res }}$ can be achieved through the instantaneous sampling of the in-cylinder gas at IVC, but this procedure is rarely applied due to the specific instrumentation required [46].

In case that experimental estimates are not available, the calculation of $m_{r e s}$ and $m_{s c}$ could be done by means of 3D Computational Fluid Dynamics (CFD) calculations or 1D fluid-dynamic models. However, these methods are highly time-consuming and usually require a large number of geometrical data along with an important calibration work, often for each operating condition. Hence they are not suitable tools neither to be coupled to a thermodynamic OD model to perform combustion analysis from in-cylinder pressure [47] nor to perform simple predictive estimations [48]. A good alternative to 3D and 1D modeling is provided by filling-and-emptying models with quasi-steady flow hypotheses [49]. Nevertheless they have a main drawback: in 2-stroke engines, the 0D assumptions in the chamber are usually inadequate due to the complex $3 \mathrm{D}$ phenomena occurring during the scavenging process, thus leading to important uncertainties in the estimation of $m_{\text {res }}$ and $m_{s c}$

Taking into account the above comments, and considering the necessity of developing a reliable methodology to determine the mass at IVC in a 2-stroke high speed direct injection diesel engine, the aim of this work is to propose a physical model for estimating the residual mass $m_{r e s}$. The estimator is conceived so as to require a limited number of inputs: instantaneous in-cylinder pressure, intake temperature, air and fuel mass flows, short-circuited mass $m_{s c}$ (obtained from the experimental determination of TR) and a number of physical constants to be tuned as detailed below. The basis of the model is a mass and energy balance in the chamber, as in OD filling and emptying models; however, its predictive capabilities are enhanced with respect to those models by means of the use of the experimental incylinder pressure as the main input of the model. In-cylinder pressure will be used to account for the expansion of the residual gas during the exhaust process and its later evolution during the intake period until IVC. A suitable calibration of the polytropic exponents during the expansion and intake periods will be performed by means of $1 \mathrm{D}$ modeling. The outcome of the proposed model is a precise $m_{\text {res }}$ estimation that allows to accurately set the mass and temperature at IVC to be used in models dealing with the in-cylinder processes during the closed cycle, including (but not limited to) OD models for combustion analysis purposes.

Even though the proposal and its validation are both focused on a 2-stroke Diesel engine, the same thermodynamic approach with a specific calibration procedure should allow its use in other 2-stroke or 4-stroke reciprocating engines, either diesel or gasoline.

\section{Methodology and tools}

For the measurements required and the tuning and validation of the residual mass estimator, different experimental and modeling tools were used. This section is devoted to the description of the experimental facility and the detailed 1D wave action model used to adjust and validate the estimator. The 1D model was built and calibrated with the purpose to calculate the residual mass from the experimental data obtained in the target engine, and was later used to evaluate the accuracy of the proposed models in a numerical experiment.

\section{Experimental facility}

A 2-stroke High Speed Direct Injection (HSDI) Compression Ignition (CI) engine with poppet valves, and equipped with a Variable Valve Timing (VVT) system to control the phasing of the intake and exhaust camshafts was selected, due to its suitability for model validation. The most relevant engine characteristics are detailed in Table 1. This particular engine and its scavenge and combustion performance have been deeply investigated by the authors during previous studies, with a wide operating range and under two different combustion concepts such as Conventional Diesel Combustion (CDC) [50], and Partially Premixed Combustion (PPC) using gasoline as fuel [51, 52]. 
The residual mass on this type of engine is particularly high due to its scavenge performance, and the final residual mass level can be controlled in a wide range by adjusting the VVT system and the pressure drop between the intake and exhaust manifolds.

\section{[Table 1 about here.]}

[Figure 1 about here.]

The engine is installed into a fully instrumented test cell according to the scheme shown in Fig. 1, which includes measurement devices for engine performance and emissions, and also for detailed parameters concerning engine control. A controlled mass flow of compressed air (oil and waterfree) is provided by an external compressor to simulate boost conditions at the intake. The exhaust back-pressure is reproduced and controlled by means of a throttle valve located in the exhaust line downstream of the exhaust settling chamber. The experimental facility also includes a low pressure EGR system, designed to provide arbitrary levels of cooled EGR even at very high intake boost pressures. Intake and exhaust pressure are measured with piezoresistive sensors, while their temperatures are measured with thermocouples. In-cylinder pressure is measured with a piezoelectric sensor, whereas an additional piezoresistive pressure sensor is located at the cylinder liner close to Bottom Dead Center (BDC) in order to provide a reference for the piezoelectric sensor pressure signal. All highfrequency signals are sampled with a resolution of 0.2 crankangle degrees (CAD).

The trapping ratio, defined as the ratio between the mass of charge delivered that has been trapped inside the cylinder before combustion and the mass of charge supplied to the cylinder (fresh air + EGR), is experimentally measured in each engine operating point using methane $\left(\mathrm{CH}_{4}\right)$ as a tracer gas [42, 43]. A certain concentration (approx. 1000 ppm) is injected in the intake manifold to be mixed with the fresh air and then, assuming that the trapped methane is completely burned during combustion, its molar fraction is measured at the exhaust in order to calculate the trapped mass fraction. The exhaust gases are sampled close to the exhaust settling chamber and routed to a state-of-theart HORIBA 7100 DEGR gas analyzer by a heated pipe to ensure gas temperatures above $150{ }^{\circ} \mathrm{C}$. This device provides the molar fraction of the different gases $\left(\mathrm{O}_{2}, \mathrm{CO}, \mathrm{CO}_{2}, \mathrm{HC}\right.$, $\mathrm{NO}_{\mathrm{X}}, \mathrm{N}_{2} \mathrm{O}$ and $\mathrm{CH}_{4}$ ) and the EGR rate.

The most relevant global parameters related to the combustion process, such as the indicated mean effective pressure (IMEP), start of combustion (SoC) and combustion phasing (CA10 and CA50), maximum cylinder pressure, pressure gradient and noise, combustion stability, rate of heat release (RoHR) and cylinder mean gas temperature, are calculated from the cylinder pressure signal with an inhouse OD combustion analysis software CALMEC [39]. The OD model simplifies the phenomena occurring inside the engine cylinder, and thus cannot provide any information related to local thermochemical conditions. However, the different combustion profiles and their characteristics stand as experimental references to calibrate the $1 \mathrm{D}$ model of the engine, which will be used to generate combustion simulations for designs of experiments.

\section{Combustion analysis and gas-dynamic model}

As mentioned previously, combustion analysis is performed with the in-house software CALMEC [39], by starting from in-cylinder pressure to solve the first law of thermodynamics and obtain the Rate of Heat Release (RoHR) and complementary data related to the combustion process. Specific sub-models for heat transfer to the chamber walls, mechanical deformations, blow-by leakage, fuel injection and instantaneous variation of gas properties are considered. From the heat release, main characteristic combustion parameters such as the Start of Combustion (SoC), ignition delay or combustion angles (CA10, CA50, CA90), are calculated.

A $1 D$ version of the engine was modeled through the OpenWAM software. OpenWAM is an in-house wave action model developed for the gas dynamics modeling of internal combustion engines. It solves the thermo- and fluid-dynamic equations in each part of the engine, by computing the different elements by the means of OD or 1D objects connected by suitable boundary conditions. A 1D gas dynamics model performs the calculations of the flow properties along the intake and exhaust systems as well as the EGR paths. All the relevant phenomena taking place along the ducts are considered, including wave interactions, which have an important effect on volumetric efficiency (especially in the intake/exhaust manifolds), the species transport (the thermodynamic properties of the gas depend on the composition and the temperature), the heat transfer between the gas and the duct walls, and the friction between gas and walls. All these fluid-dynamic computations are implemented in detail through the method described by Galindo et al. [53, 54].

Additionally to the fluid calculations, the gas-dynamic model is coupled to a cylinder model that predicts the in-cylinder conditions based on the combustion process, where a detailed heat transfer model is used to obtain 
the heat rejection to the chamber walls. This combustion model is based on the Apparent Combustion Time (ACT) concept, which consists in a zero-dimensional approach to the combustion process in Diesel engines used to obtain a global and simplified description of the processes that take place in the combustion chamber [14, 15, 55]. This ACT model describes the relation between the running conditions of the engine and the Rate of Heat Release (RoHR). Those two models combined lead to the development of a reference virtual engine which allows the calculation of the Internal Gas Residuals (IGR) rate (among other relevant magnitudes) that can be used as a target for the estimator.

Once correctly calibrated, it is a well fitted tool to emulate the engine behavior, in order to run a large number of simulations much faster, less costly, and in more stable conditions (for repetitive iterations as in the DoE cases described later in this paper) than experimental tests.

\section{Methodology}

The work performed here was based on a reference engine operating point at $2500 \mathrm{rpm}$ and 15 bar of Indicated Mean Effective Pressure (IMEP). However, all the methodology presented in the following study can be transposed to any operating point.

The 1D model OpenWAM was used to simulate the engine behavior after a fine calibration: CFD calculations were performed to get the scavenge profile (Fig. 2) and the boundary conditions, while the ACT combustion model was calibrated to reproduce the engine thermodynamics. The CFD results concerning the boundary conditions are very similar to the experimental data (Trapping Ratio of $80 \%$ while the measurement stands at $81.8 \%$ ), except for the IGR that was experimentally measured through the simple model presented here (CFD estimated $21 \%$ while experiments gave $30 \%)$.

\section{[Figure 2 about here.]}

By comparing the simulation with experimental results in terms of in-cylinder pressure (Fig. 3 left plot) and intake and exhaust pressures (Fig. 3 right plot), the WAM model seems to be a very reliable tool for the open cycle as well as for the closed cycle.

[Figure 3 about here.]

This 1D model could then be used to generate outputs which were not directly available experimentally, such as the residuals mass. In addition, such a model allows fast calculations, which is a non-negligible advantage considering the chosen methodology consisting of Designs of Experiments (DoE) for two operating points and four input parameters. The configuration and results of these DoEs are presented in detail later in this paper.

Then, from the experimental results and the CALMEC calculations, the estimator was developed by solving the thermodynamic laws at several levels of complexity. The first level consisted of a basic solution for a fast application and online calculations on the engine test bench. In a second step, a more complex approach was considered, assuming polytropic processes during the scavenging. This method is much more realistic but also requires more calculation time, so it may not be easily adaptable for a direct application on a test cell.

Finally, the results of the different estimators were compared to OpenWAM simulations (IGR mass, temperature of the residuals, temperature at IVC...) and, in the case of the polytropic models, those simulations were used as reference to calibrate the polytropic coefficients of the estimator.

\section{Model description}

The IGR estimator is based on the application of two fundamental thermodynamic balances at IVC, the mass balance (Eq. 2) and the enthalpy balance (Eq. 3). The conditions at IVC are the result of combining the conditions of the intake trapped air and the residual gases retained from the previous cycle. In addition, all gases and particularly those retained inside the cylinder at IVC are considered ideal (Eq. 4). Thus, the three main equations of the system can be expressed as:

$$
\begin{gathered}
m_{I V C}=m_{t r}+m_{r e s} \\
m_{I V C} \cdot h_{I V C}=m_{t r} \cdot h_{t r}+m_{r e s} \cdot h_{r e s} \\
P_{I V C} \cdot V_{I V C}=m_{I V C} \cdot R_{I V C} \cdot T_{I V C}
\end{gathered}
$$

The enthalpy balance (Eq. 3) is rewritten by expressing the enthalpies as a function of the corresponding heat capacities $c_{p}$ and the temperatures (Eq. 5) - (Eq. 7):

$$
\begin{gathered}
h_{I V C}=\int_{T_{0}}^{T_{I V C}} c_{p_{I V C}} \cdot d T \\
h_{t r}=\int_{T_{0}}^{T_{t r}} c_{p_{t r}} \cdot d T \\
h_{r e s}=\int_{T_{0}}^{T_{r e s}} c_{p_{r e s}} \cdot d T
\end{gathered}
$$


The three main equations, plus the expressions of the sensible enthalpies (no chemical reaction is considered), provide six equations and fifteen unknowns, which are three masses from (Eq. 2) $\left(m_{I V C}, m_{t r}\right.$ and $\left.m_{r e s}\right)$, three enthalpies from (Eq. 3) $\left(h_{I V C}, h_{t r}, h_{r e s}\right), P_{I V C}, V_{I V C}$ and $R_{I V C}$ from (Eq. 4), and three heat capacities and three temperatures from (Eq. 5) - (Eq. 7) $\left(c_{p_{I V C}}, c_{p_{t r}}, c_{p_{\text {res }}}\right.$, and $\left.T_{I V C}, T_{t r}, T_{r e s}\right)$. However, some of these unknowns are either defined directly by the geometry or measured, whence they are independent from the chosen resolution method.

\section{Definition of the geometric and measured parameters}

The cylinder volume at IVC $\left(V_{I V C}\right)$ is set geometrically knowing the position of the piston as a function of the angle. Also, $P_{I V C}$ is obtained directly from the referenced cylinder pressure measurement. The trapped mass $m_{t r}$ is decomposed into various components, each one being measured separately:

$$
m_{t r}=\eta_{t r} \cdot m_{t o t}^{i n t}=\eta_{t r} \cdot\left(m_{a}+m_{E G R}\right)
$$

As indicated above, the trapping efficiency or trapping ratio $\left(\eta_{t r}\right)$ is measured following the tracer gas methodology (injecting methane into the intake port [42, 43]), and the calculation process is detailed in Appendix A. The fresh air supplied to the engine $\left(m_{a}\right)$ is measured through a volumetric flow-meter and the EGR mass $\left(m_{E G R}\right)$ is calculated as a proportion of the total mass admitted:

$$
m_{E G R}=m_{t o t}^{i n t} \cdot T_{E G R}=m_{a} \cdot \frac{T_{E G R}}{1-T_{E G R}}
$$

The EGR rate $\left(T_{E G R}\right)$ is defined, according to its common definition, as the $\mathrm{CO}_{2}$ molar fraction ratio between intake and exhaust gases, and measured by the gas analyzer:

$$
T_{E G R}=\frac{X_{C O_{2}}^{i n t}}{X_{C O_{2}}^{e x h}}
$$

The EGR mass is then expressed as:

$$
m_{E G R}=m_{a} \cdot \frac{X_{\mathrm{CO}_{2}}^{i n t}}{X_{\mathrm{CO}_{2}}^{e x h}-X_{\mathrm{CO}_{2}}^{i n t}}
$$

The number of unknowns is then reduced down to twelve. In order to solve the system, six more equations or hypotheses are required. Then and as decribed next, different thermodynamic models may be considered, depending on the assumptions considered for the thermodynamic properties of the fluids.

\section{Basic thermodynamic model}

In the simplest option, the mass balance is as defined by equation (Eq. 2) while the perfect gas assumption is considered for all gases, so that the heat capacities in (Eq. 5) - (Eq. 7) are assumed to be constant and known. The equation (Eq. 3) can be rewritten as (Eq. 12).

$$
\begin{aligned}
m_{I V C} \cdot c_{p_{I V C}} \cdot T_{I V C} & =m_{t r} \cdot c_{p_{t r}} \cdot T_{t r} \\
& +m_{r e s} \cdot c_{p_{r e s}} \cdot T_{r e s}
\end{aligned}
$$

In addition, $R_{I V C}$ is also considered constant in (Eq. 4) and known.

This process generates a set of three equations (Eq. 2) (Eq. 4) (Eq. 12) with five unknowns $\left(m_{I V C}\right.$, $\left.m_{r e s}, T_{I V C}, T_{t r}, T_{r e s}\right)$, so that two additional hypotheses must be assumed in order to close this basic model. In this case, an attractive option for its simplicity consists of considering the temperatures of the trapped mass and the residuals equal to the intake and the exhaust temperatures, respectively.

$$
\begin{gathered}
T_{t r}=T_{i n t} \\
T_{\text {res }}=T_{e x h}
\end{gathered}
$$

Therefore, the problem is finally closed and it can be solved analytically giving (Eq. 15).

$$
m_{r e s}=\frac{c_{p_{I V C}} \cdot \frac{P_{I V C} \cdot V_{I V C}}{R_{I V C}}-m_{t r} \cdot c_{p_{t r}} \cdot T_{t r}}{c_{p_{r e s}} \cdot T_{r e s}}
$$

Then, the mass at IVC $\left(m_{I V C}\right)$ can be obtained directly from the mass balance (Eq. 2):

$$
m_{I V C}=m_{t r}+m_{r e s}
$$

The temperature at IVC can also be calculated from the ideal gas equation (Eq. 4).

$$
T_{I V C}=\frac{P_{I V C} \cdot V_{I V C}}{m_{I V C} \cdot R_{I V C}}
$$

As a final remark, this basic model has the clear benefit of being very simple and extremely fast, making it compatible with real-time applications such as control or on-line test cell data analysis during the experimental activities. However, some of the assumptions can introduce unacceptable errors depending on the particular engine characteristics, operating conditions, etc., and therefore its accuracy will be carefully evaluated in the next section. 


\section{Detailed thermodynamic model}

This model is based on a more realistic description of the thermodynamic properties of the fluids and of the processes occurring in the engine, but the calculations are also more complex and time-consuming. The new assumptions are expected to improve the accuracy of the estimate of the residuals and of the total trapped mass with respect to those generated with the previous basic model.

In this model, as in the simple model, the mass balance is as defined by equation (Eq. 2), and the enthalpy balance corresponds to equation (Eq. 3), with enthalpies expressed as a function of heat capacities (Eq. 5) - (Eq. 7). However, the previous hypotheses of perfect gases is not assumed anymore and the heat capacities are now expressed as a function of the composition of the gases and their temperatures.

The enthalpy balance (Eq. 3) is then rewritten considering the previous dependencies to derive equation (Eq. 18).

$$
\begin{array}{r}
m_{I V C} \cdot \int_{T_{0}}^{T_{I V C}} c_{p_{I V C}}\left(T, Y_{b}^{I V C}\right) \cdot d T= \\
m_{t r} \cdot \int_{T_{0}}^{T_{t r}} c_{p_{t r}}\left(T, Y_{b}^{t r}\right) \cdot d T+ \\
m_{r e s} \cdot \int_{T_{0}}^{T_{r e s}} c_{p_{r e s}}\left(T, Y_{b}^{r e s}\right) \cdot d T
\end{array}
$$

As a result, the heat capacities of the trapped mass, the residual mass or the total mass at IVC are calculated from their composition in terms of the fraction of fresh air and burnt gases in stoichiometic conditions, and their corresponding temperatures, according to the set of equations (Eq. 19) - (Eq. 21).

$$
c_{p_{I V C}}=Y_{a}^{I V C} \cdot c_{p_{a}}\left(T_{I V C}\right)+Y_{b}^{I V C} \cdot c_{p_{b}}\left(T_{I V C}\right)
$$

$$
\begin{gathered}
c_{p_{t r}}=Y_{a}^{t r} \cdot c_{p_{a}}\left(T_{t r}\right)+Y_{b}^{t r} \cdot c_{p_{b}}\left(T_{t r}\right) \\
c_{p_{\text {res }}}=Y_{a}^{r e s} \cdot c_{p_{a}}\left(T_{r e s}\right)+Y_{b}^{r e s} \cdot c_{p_{b}}\left(T_{r e s}\right)
\end{gathered}
$$

For simplicity, the dependency of the heat capacities with temperature is defined by means of polynomial correlations only for fresh air with standard composition and burnt gases in stoichiometric conditions, following an approach similar to that suggested by Lapuerta et al. [12]. At this point, it is important to recall that the temperatures in equations (Eq. 18) - (Eq. 21), have already been defined as unknowns. Considering that the different gases are composed only by fresh air and burnt gases in stoichiometric conditions, their mass fractions are complementary according to $Y_{a}^{x}=1-Y_{b}^{x}$ with $x$ standing for either $I V C$, $t r$ or res.

The fraction of burnt gases in stoichiometric conditions in the trapped mass, the residual mass or the total mass at IVC are obtained solving the set of equations defined by the mass balances at the intake, in the cylinder at IVC and at EVO, and finally at the exhaust as discussed in Appendix B. Then, the expressions of these mass fractions depend only on variables that were either already included in the solution as unknowns (Eq. 22) - (Eq. 24) or obtained experimentally (not included in the set of equations to highlight the unknowns of the problem).

$$
Y_{b}^{I V C}=f\left(m_{I V C}, m_{t r}, m_{r e s}, Y_{b}^{t r}, Y_{b}^{r e s}\right)
$$

$$
Y_{b}^{t r}=Y_{b}^{e x h} \cdot T_{E G R}=f\left(m_{t r}, Y_{b}^{r e s}\right)
$$

$$
Y_{b}^{r e s}=Y_{b}^{E V O}=f\left(m_{t r}\right)
$$

Concerning the ideal gas assumption, it is still accepted and expressed as equation (Eq. 4), except that $R_{I V C}$ now depends on the composition of the mass at IVC (Eq. 25), assuming constant and known values for $R_{a}$ and $R_{b}$ :

$$
R_{I V C}=Y_{a}^{I V C} \cdot R_{a}+Y_{b}^{I V C} \cdot R_{b}
$$

Since no new unknowns are added to the problem, a total of nine unknowns $\left(m_{I V C}, m_{r e s}, Y_{b}^{x}, T_{x}, R_{I V C}\right)$ and seven equations (Eq. 2) - (Eq. 4) plus (Eq. 22) - (Eq. 25) can be identified. In this way, two hypotheses must be formulated about the temperatures of the trapped mass and of the residuals in order to close the problem. With the purpose of retaining as much thermodynamic consistency as possible, polytropic evolutions were assumed to relate the intake manifold temperature to the temperature of the trapped mass at IVC, and the temperature of the residuals at IVC with the temperature at EVO.

For the trapped mass, only one polytropic process was considered to evaluate its temperature at IVC, as expressed by equation (Eq. 26):

$$
T_{t r}=T_{i n t} \cdot\left(\frac{P_{i n t}}{P_{I V C}}\right)^{\frac{1-k_{i n t}}{k_{i n t}}}
$$

For the residual gases, the same approach with a single polytropic process between EVO and IVC was initially evaluated, but it was readily apparent that the temperature evolution of the residuals during this process cannot be well 
reproduced by considering a thermodynamic process with only one polytropic coefficient, as shown by the blue curve in Fig 4. Furthermore, in order to be able to reach the final residuals temperature predicted by the $1 \mathrm{D}$ model OpenWAM, this coefficient would need be set at a value of 20 , which is thermodynamically incoherent.

\section{[Figure 4 about here.]}

However, by decomposing the exhaust process into two polytropic evolutions with different coefficients, the evolution of the gas temperature appears to be much better estimated (green curve in Fig 4). Therefore, this option based on two polytropic processes was considered, the first accounting for the blow-down stage between EVO and the minimum cylinder pressure (Eq. 27), and the second accounting for the conventional scavenging exhaust stage (Eq. 28).

$$
\begin{gathered}
T_{r e s, P_{\text {min }}}=T_{r e s, E V O} \cdot\left(\frac{P_{E V O}}{P_{\text {min }}}\right)^{\frac{1-k_{e x h 1}}{k_{e x h 1}}} \\
T_{r e s}=T_{r e s, P_{\text {min }}} \cdot\left(\frac{P_{\text {min }}}{P_{I V C}}\right)^{\frac{1-k_{e x h 2}}{k_{e x h 2}}}
\end{gathered}
$$

In these polytropic processes, all the pressures are experimentally measured, as well as the intake temperature. Then, four new unknowns can be identified $\left(T_{r e s, E V O}, k_{i n t}\right.$, $\left.k_{e x h 1}, k_{e x h 2}\right)$. By applying the ideal gas equation (Eq. 4) at EVO, the pressure and volume are known from the geometry and measurements, the mass depends on the mass at IVC (already included in the equations system), the mass of fuel and the blow-by (both measured), and $R_{E V O}$ is a function of the gas composition already expressed by equation (Eq. 24). This new equation is then added to the system to solve $T_{\text {res, EVO }}$ (Eq. 29).

$$
T_{r e s, E V O}=\frac{P_{E V O} \cdot V_{E V O}}{m_{E V O} \cdot R_{E V O}}
$$

Finally, the problem is formulated in terms of eleven unknowns ( $m_{I V C}, T_{I V C}, m_{r e s}, Y_{b}^{x}, R_{I V C}, T_{r e s, E V O}, k_{i n t}$, $\left.k_{\text {exh } 1}, k_{\text {exh } 2}\right)$ when two polytropic processes are considered for the residuals, related by eight equations (Eq. 2) (Eq. 4) plus (Eq. 22) - (Eq. 25) plus (Eq. 29). Then, some assumption about the values of the polytropic coefficients $k_{x}$ was needed to close the model; however, it was expected that they could be easily calibrated (through 1D models, for instance) in view of their well-known order of magnitude and their relatively narrow interval of acceptable values.

\section{Results and discussion}

As discussed previously, a 1D-model of the engine was developed with OpenWAM. For the work presented here, the most critical part of the engine cycle is the open cycle, from EVO to IVC. In a 2-stroke engine, the pressure waves in both the intake and exhaust manifolds have a great influence on engine efficiency, and therefore careful consideration should be given to the correlation of the exhaust and intake pressures. Fig. 3 shows the results of this calibration, and it can be observed that the wave model is qualitatively very similar to the real conditions (the pressure waves are very well phased), even if there are some small quantitative deviations. Thus, this model can be used as a reference for the non-measurable parameters and to confront with the residual mass estimator results.

As shown in Table 2, all the measured parameters such as the intake or exhaust temperature and pressure, or the intake air mass, are very close to the values estimated from the model (less than $1.8 \%$ error). However, the non-measurable parameters (mass at IVC and IGR rate) are calculated with the simple estimator and appear to be substantially overestimated, with an error above $40 \%$, confirming the need to develop a reliable tool for the estimation of the residual mass.

[Table 2 about here.]

\section{Validation of the residual mass estimator}

In order to validate the IGR estimator, two DoEs, at different operating points, were used, one at medium load and low engine speed, and the other at high load and high engine speed.

These DoEs were created from experimental measurements performed on the engine, and the twenty-five corresponding points were calculated by means of the OpenWAM model. For each point, the calculated IGR rate was compared to the prediction from the simple estimator (used on the engine test bench). Simultaneously, the proposed detailed estimator (based on polytropic processes) was adjusted with the results from OpenWAM and from the measurements to properly estimate the residuals fraction and the trapped mass. In this way, direct comparison between the results obtained with the $1 \mathrm{D}$ model and those from the estimators was possible.

Set up of the DoEs The real operating conditions on which the two DoEs were based are presented in Table 3. Four parameters were then selected as inputs for the DoEs: the pressures at the intake and at the exhaust $\left(P_{\text {int }}\right.$ and $\left.P_{\text {exh }}\right)$, 
thus setting the pressure drop $(\Delta P)$, and the phasing of the intake and the exhaust camshafts $\left(V V T_{i n t}\right.$ and $\left.V V T_{\text {exh }}\right)$, thus setting the overlap (Olap).

\section{[Table 3 about here.]}

The configurations of the DoEs are presented in Appendix C, where the parameters for each of the twentyfive points are detailed. For each DoE, each point was calculated with the OpenWAM model, and compared to those obtained from the simple estimator, providing a wide basis for comparison at various scavenging conditions.

Results from the DoEs and comparison between the OpenWAM model and the estimators As shown in Fig 5 (and detailed in Appendix D, see Table 6 and Table 7), the mean error between the OpenWAM model and the simple IGR estimator is around $4 \%$ in absolute value, with a peak at more than $6 \%$ for some conditions.

The calibration of the detailed estimator was performed by adjusting the polytropic coefficients for each operating point, thus obtaining: $k_{\text {exh } 1}=1.4$ and $k_{\text {exh } 2}=1.2$. As a first approach, the polytropic coefficient for the trapped mass is fixed at $k_{i n t}=1.35$. As shown in Fig 5, the mean error is drastically reduced to around $1.4 \%$ for DoE 1 , and $0.5 \%$ for DoE 2.

\section{Adjustments of the polytropic coefficients}

[Figure 5 about here.]

The estimate of the residuals fraction is noticeably improved by the use of the detailed IGR estimator with respect to the simple one, as shown in Fig. 5, where the first version of the detailed estimator is represented by the orange plot. It can be observed that the trend from the WAM model is followed very closely, which was not the case with the simple estimator (for instance, between the third and fourth points of DoE 1 , the IGR rate should decrease, but increases with the simple estimator). However, the precision can still be improved with some fine-tuning of the polytropic coefficient for the trapped mass (initially set to $k_{i n t}=1.35$ ).

Indeed, the IGR rate is still underestimated due to a too high polytropic coefficient (hence a too low heat transfer) for the fresh intake air. A new value of $k_{i n t}=1.30$ was selected to increase the heat transfer to the intake air, but ensuring that it should still be lower than that of the residuals (since the temperature difference between the residuals and the cylinder wall should be higher than that between the intake ducts and the fresh air). Then, the DoEs were repeated using $k_{\text {int }}=1.30$, and the results are represented by the blue plot in Fig. 5.
[Figure 6 about here.]

The previous study was then repeated for all the points of the two DoEs with a polytropic coefficient for the trapped mass of $k_{i n t}=1.3$. In both operating points a slight improvement can be observed, with a mean difference of around $0.2 \%$ (even $0.02 \%$ for DoE 1) and a maximum difference below $1 \%$. The detailed results (data corresponding to Fig. 5) are given in Appendix D.

Another factor that needs to be considered in the validation is the sensitivity of the estimator to the engine parameters, as represented in Fig. 6 where the IGR rate is expressed as a function of the various parameters from the DoEs (each one being successively taken as a variable whereas the other ones are kept constant). Aside from the quantitative error already demonstrated in Fig. 5, it can be observed here that at low load (DoE 1), the response of the simple model is consistent with the WAM reference for the intake pressure variations, but loses sensitivity when changing the pressure drop or the valve overlap. At higher load (DoE 2), the sensitivity is also lost when the intake valve timing is modified. On the contrary, the detailed model keeps a good sensitivity compared to the WAM reference, regardless of the parameter studied.

\section{[Figure 7 about here.]}

As a final check, the detailed version of the residuals estimator was compared to the simple one used previously on the engine, and implemented into CALMEC to calculate the heat release for various operating points. As the heat release calculation is more affected by the residual mass fraction when low loads are considered, the validation was focused on points with IMEP ranging from 3 to 5 bar. As shown in Fig. 7, the residuals mass is not overestimated anymore, and thus a larger part of the energy released by combustion is transformed into indicated energy. This results in an apparent combustion efficiency (calculated as the ratio between the maximum cumulative heat release and the fuel chemical energy) more similar to the real combustion efficiency calculated from $\mathrm{HC}$ and $\mathrm{CO}$ measurements. Moreover, the detailed model is free from the unphysical phenomena observed with the simple estimator before the start of combustion (a negative heat release mathematically compensating for the over-estimated mass).

\section{[Figure 8 about here.]}

The other parameters relevant for the validation are the incylinder temperature, which affects directly the heat transfer, and the global composition inside the cylinder. As it can 
be seen in Fig. 8, the variation of the IGR rate has a deep impact on the in-cylinder temperature thus affecting importantly the heat rejection to the chamber walls. As the heat transfer plays a key role in the energy balance of the engine $[56,57,58]$, the behavior seen in Fig. 7 (that is, the negative heat release before the start of combustion) can also be justified mainly by the uncertainty in this term. According to these comments, it can be concluded that improving the residuals estimation has a global impact on the combustion diagnostic.

Finally, both the temperature and the cylinder composition are very important to better understand the link between combustion and pollutant emissions, as they determine the combustion conditions and the resulting adiabatic flame temperature.

\section{Conclusion}

In response to the necessity of evaluating the mass of the residual burnt gases inside the cylinder, several versions of an IGR estimator have been developed, from a simple and easily manageable tool for direct application in the engine test bench, to a more detailed and accurate, but also more time-consuming, thermodynamic model. It was prescribed that the only inputs required by the estimator should be the basic magnitudes usually measured in an engine (pressures, temperatures, EGR rate, TR, etc.), in order to avoid specific equipment or engine adaptation. The methodology used to develop the model consisted simply of the application of thermodynamics to the different phases of the engine cycle.

Once the model was developed, a validation methodology was mandatory in order to assure its consistency. The scavenging process was analyzed by means of 3D CFD simulations, whose results were subsequently used to calibrate an OpenWAM 1D model of the engine, which would then be used as a reference engine. Two 25-points DoEs were designed at two operating points and the IGR rates obtained with the different versions of the estimator were compared to the results from the reference OpenWAM engine. A significant improvement was achieved when changing for the simple estimator to the detailed version, in terms of the accuracy of the estimates of the residual mass and the total mass at IVC, with a reduction in the relative error as well as exhibiting more consistent trends. Finally, the detailed version was incorporated into the combustion diagnosis tool CALMEC to re-evaluate experimental tests and compare the results with those obtained with the simple estimator. More realistic results concerning the combustion process and the heat transfer were achieved, presenting more physically sensible heat release profiles regardless of the operating conditions considered.

Eventually, the two versions of the IGR estimator have complementary applications. The simple model, even if not as accurate, allows fast calculations and real-time estimates directly at the test bench. The detailed version is not as easily manageable for such an application, but provides very accurate evaluations of the mass of residual burnt gases inside the cylinder for off-line analyses, in particular for combustion diagnosis, as this requires good precision and high levels of physical background to provide consistent results in terms of heat release or heat transfer calculations, and also for the proper estimation of pollutant emissions with chemical models. 


\section{Nomenclature}

$\begin{array}{ll}\eta_{t r} & \text { Trapping efficiency (Trapping Ratio) } \\ A F R_{s t} & \text { Stoichiometric Air/Fuel Ratio } \\ C A D & \text { Crank Angle Degree } \\ c_{p} & \text { Thermal coefficient of the mixture } \\ c_{p_{a}} & \text { Thermal coefficient of the fresh air } \\ c_{p_{b}} & \text { Thermal coefficient of the burnt gases } \\ c_{p_{I V C}} & \text { Thermal coefficient of the mixture at IVC } \\ c_{p_{r e s}} & \text { Thermal coefficient of the residuals } \\ c_{p_{t r}} & \text { Thermal coefficient of the trapped mass } \\ E G R & \text { Exhaust Gas Recirculation } \\ E V O & \text { Exhaust Valve Opening (angle) } \\ h_{I V C} & \text { Enthalpy of the mixture at IVC } \\ h_{r e s} & \text { Enthalpy of the residuals } \\ h_{t r} & \text { Enthalpy of the trapped mass } \\ I G R & \text { Internal Gas Recirculation } \\ I M E P & \text { Indicated Mean Effective Pressure } \\ I V C & \text { Intake Valve Closing (angle) } \\ k_{e x h 1} & \text { Polytropic coefficient during the expansion } \\ k_{e x h 2} & \text { Polytropic coefficient during scavenging } \\ k_{i n t} & \text { Polytropic coefficient at the intake } \\ m_{a, b} & \text { Burnt air mass } \\ m_{a} & \text { Fresh air mass at the intake } \\ m_{b b} & \text { Blow-by mass } \\ m_{C H}^{e x h} & \text { Methane mass at the exhaust } \\ m_{C H}^{i n t} & \text { Methane mass at the intake } \\ m_{C H}^{t r} & \text { Methane trapped mass } \\ m_{E G R} & \text { EGR mass } \\ m_{E V O} & \text { Total mass at EVO } \\ m_{f} & \text { Fuel mass } \\ m_{f, b} & \text { Burnt fuel mass } \\ m_{I V C} & \text { Total mass at IVC } \\ m_{r e s} & \text { Residual mass } \\ m_{s c} & \text { Short-circuited mass } \\ m_{t o t}^{i n t} & \text { Total mass at the intake } \\ m_{t r} & \text { Total trapped mass } \\ P_{E V O} & \text { Cylinder pressure at EVO } \\ P_{I V C} & \text { Cylinder pressure at IVC } \\ P_{m i n} & \text { Minimum cylinder pressure } \\ & \end{array}$

$P_{\text {int }}$

$R_{a}$

$R_{b}$

$R_{E V O}$

$R_{I V C}$

$T_{E G R}$

$T_{\text {exh }}$

$T_{0}$

$T_{\text {int }}$

$T_{I V C}$

$T_{\text {res }}$

$T_{\text {res, EVO }}$

$T_{\text {res }, P_{\text {min }}}$

$T_{t r}$

$T_{x}$

$T R$

$V_{E V O}$

$V_{I V C}$

$V V T$

$V V T_{\text {in }}$

$V V T_{e x}$

$\mathrm{X}_{\mathrm{CH}}^{\mathrm{exh}}$

$X_{C H_{4}}^{i n t}$

$\mathrm{X}_{\mathrm{CO}}^{e x h}$

$\mathrm{X}_{\mathrm{CO} \mathrm{O}_{2}}$

$Y$ IVC

$Y_{a}^{r e s}$

$Y_{a}^{t r}$

$Y_{b}^{b b}$

$Y_{b}^{c y l}$

$Y_{b}^{E V O}$

$Y_{b}^{e x h}$

$Y_{b}^{\text {int }}$

$Y_{b}^{I V C}$

$Y_{b}^{r e s}$

$Y_{b}^{t r}$

$Y_{C H_{4}}^{e x h}$

$Y_{\mathrm{CH}_{4}}^{\text {int }}$
Intake pressure

Ideal gas constant for fresh air

Ideal gas constant for burnt gases

Ideal gas constant for mixture at EVO

Ideal gas constant for mixture at IVC

EGR rate

Exhaust temperature

Standard temperature

Intake temperature

Cylinder temperature at IVC

Temperature of the residuals

Temperature of the residuals at EVO

Temperature of the residuals at min. cyl. pres.

Temperature of the trapped mass

Temperature of specie $x$

Trapping Ratio

Cylinder volume at EVO

Cylinder volume at IVC

Variable Valve Timing

Intake Variable Valve Timing

Exhaust Variable Valve Timing

Methane molar fraction at the exhaust

Methane molar fraction at the intake

Carbon dioxide molar fraction at the exhaust

Carbon dioxide molar fraction at the intake

Mass fraction of fresh air at IVC

Mass fraction of fresh air in the residuals

Mass fraction of fresh air in trapped mass

Mass fraction of burnt gases in blow-by

Mass fraction of burnt gases in the cylinder

Mass fraction of burnt gases at EVO

Mass fraction of burnt gases at the exhaust

Mass fraction of burnt gases at the intake

Mass fraction of burnt gases at IVC

Mass fraction of burnt gases in the residuals

Mass fraction of burnt gases in trapped mass

Methane mass fraction at the exhaust

Methane mass fraction at the intake

\section{Acknowledgements}

This research has been sponsored by the European Union in framework of the REWARD project, Horizon 2020 research and innovation program under grant agreement No.636380. The authors kindly recognize the technical support provided by Mr. Gilles Coma and his research group at RENAULT SAS, and also by the research group at IFPEN, along the development of the investigations presented here. 


\section{Appendices}

\section{Appendix A. Tracer method for Trapping Ratio calculation}

$$
\begin{aligned}
& \eta_{t r}=\frac{m_{t r}}{m_{a}}=\frac{m_{C H_{4}}^{t r}}{m_{C H_{4}}^{i n t}} \\
& m_{\mathrm{CH}_{4}}^{i n t}=m_{C H_{4}}^{t r}+m_{C H_{4}}^{e x h} \\
& \eta_{t r}=\frac{m_{C H_{4}}^{i n t}-m_{C H_{4}}^{e x h}}{m_{C H_{4}}^{i n t}}=1-\frac{m_{C H_{4}}^{e x h}}{m_{C H_{4}}^{i n t}}=1-\frac{Y_{C H_{4}}^{e x h} \cdot\left(m_{a}+m_{f}\right)}{Y_{C H_{4}}^{i n t} \cdot m_{a}} \\
& X_{C H_{4}}^{e x h} \approx Y_{C H_{4}}^{e x h} \\
& X_{C H_{4}}^{i n t} \approx Y_{C H_{4}}^{i n t} \\
& \eta_{t r}=1-\left(\frac{m_{a}+m_{f}}{m_{a}}\right) \cdot \frac{X_{C H_{4}}^{e x h}}{X_{C H_{4}}^{i n t}} \\
& \frac{X_{C H_{4}}^{e x h}}{X_{C H_{4}}^{i n t}}=\frac{\left(1-\eta_{t r}\right) \cdot m_{a}}{m_{a}+m_{f}} \\
& \eta_{t r}=1-\frac{m_{a}+m_{f}}{m_{a} \cdot\left(\frac{X_{C H_{4}}^{i n t}}{X_{C H_{4}}^{e x h}}+\frac{X_{C O_{2}}^{i n t}}{X_{C O_{2}}^{e x h}}\right)} \\
& \frac{X_{C H_{4}}^{e x h}}{X_{C H_{4}}^{i n t}}=\frac{\left(1-\eta_{t r}\right) \cdot m_{a}}{m_{a}+m_{f}-m_{E G R} \cdot\left(1-\eta_{t r}\right)}
\end{aligned}
$$




\section{Appendix B. Calculation of the burnt gas mass fraction at EVO}

$$
\begin{aligned}
& Y_{b}^{E V O}=\frac{m_{a, b}+m_{f, b}+m_{E G R} \cdot Y_{b}^{e x h}+m_{r e s} \cdot Y_{b}^{E V O}-m_{s c} \cdot Y_{b}^{i n t}-m_{b b} \cdot Y_{b}^{b b}}{m_{f}+m_{a}+m_{E G R}+m_{r e s}-m_{s c}-m_{b b}} \\
& Y_{b}^{b b}=\frac{Y_{b}^{I V C}+Y_{b}^{E V O}}{2} \\
& Y_{b}^{E V O}=\frac{m_{a, b}+m_{f, b}+Y_{b}^{e x h} \cdot\left(m_{E G R}-m_{s c} \cdot T_{E G R}\right)-\frac{m_{b b}}{2} \cdot Y_{b}^{I V C}}{m_{f}+m_{a}+m_{E G R}-m_{s c}-\frac{m_{b b}}{2}} \\
& Y_{b}^{E V O}=\frac{m_{a, b}+m_{f, b}+Y_{b}^{e x h} \cdot\left(m_{E G R}-m_{s c} \cdot T_{E G R}\right)-\frac{m_{b b}}{2} \cdot \frac{Y_{b}^{e x h} \cdot\left(m_{E G R}-m_{s c} \cdot T_{E G R}\right)+m_{r e s} \cdot Y_{b}^{E V O}}{m_{I V C}}}{m_{f}+m_{a}+m_{E G R}-m_{s c}-\frac{m_{b b}}{2}} \\
& =\frac{m_{a, b}+m_{f, b}+Y_{b}^{e x h} \cdot\left(m_{E G R}-m_{s c} \cdot T_{E G R}\right) \cdot\left(1-\frac{m_{b b}}{2} \cdot \frac{1}{m_{I V C}}\right)-\frac{m_{b b}}{2} \cdot \frac{m_{r e s}}{m_{I V C}} \cdot Y_{b}^{E V O}}{m_{f}+m_{a}+m_{E G R}-m_{s c}-\frac{m_{b b}}{2}} \\
& =\frac{m_{a, b}+m_{f, b}+Y_{b}^{e x h} \cdot\left(m_{E G R}-m_{s c} \cdot T_{E G R}\right) \cdot\left(1-\frac{m_{b b}}{2} \cdot \frac{1}{m_{I V C}}\right)}{m_{f}+m_{a}+m_{E G R}-m_{s c}+\frac{m_{b b}}{2} \cdot\left(\frac{m_{r e s}}{m_{I V C}}-1\right)} \\
& Y_{b}^{E V O}=\frac{m_{a, b}+m_{f, b}+\frac{\left(m_{a}+m_{f}+m_{E G R}-m_{s c}-m_{b b}\right) \cdot Y_{b}^{E V O}}{m_{f}+m_{a}+m_{E G R}-m_{b b}-m_{s c} \cdot T_{E G R}} \cdot\left(m_{E G R}-m_{s c} \cdot T_{E G R}\right) \cdot\left(1-\frac{m_{b b}}{2} \cdot \frac{1}{m_{I V C}}\right)}{m_{f}+m_{a}+m_{E G R}-m_{s c}+\frac{m_{b b}}{2} \cdot\left(\frac{m_{\text {res }}}{m_{I V C}}-1\right)} \\
& =\frac{m_{a, b}+m_{f, b}}{m_{f}+m_{a}+m_{E G R}-m_{s c}+\frac{m_{b b}}{2} \cdot\left(\frac{m_{r e s}}{m_{I V C}}-1\right)-\frac{m_{a}+m_{f}+m_{E G R}-m_{s c}-m_{b b}}{m_{f}+m_{a}+m_{E G R}-m_{b b}-m_{s c} \cdot T_{E G R}}} \\
& =\frac{m_{a, b}+m_{f, b}}{\left(m_{E G R}-m_{s c} \cdot T_{E G R}\right) \cdot\left(1-\frac{m_{b b}}{2 \cdot m_{I V C}}\right)} \\
& m_{a, b}=\frac{m_{f, b}}{A F R_{s t}} \\
& m_{f, b}+m_{a, b}=m_{f, b} \cdot\left(1+\frac{1}{A F R_{s t}}\right)=m_{f, b} \cdot\left(\frac{A F R_{s t}+1}{A F R_{s t}}\right) \\
& Y_{b}^{E V O}=\frac{m_{f, b} \cdot\left(\frac{A F R_{s t}+1}{A F R_{s t}}\right)}{m_{a}+m_{f}+m_{E G R}-m_{s c}-\left(\frac{m_{a}+m_{f}+m_{E G R}-m_{s c}}{m_{a}+m_{f}+m_{E G R}-m_{s c} \cdot T_{E G R}}\right) \cdot\left(m_{E G R}-m_{s c} \cdot T_{E G R}\right)} \\
& =\frac{m_{f, b} \cdot\left(\frac{A F R_{s t}+1}{A F R_{s t}}\right) \cdot\left(m_{a}+m_{f}+m_{E G R}-m_{s c} \cdot T_{E G R}\right)}{\left(m_{a}+m_{f}+m_{E G R}\right)^{2}-\left(m_{a}+m_{f}+m_{E G R}\right) \cdot m_{s c}-\left(m_{a}+m_{f}+m_{E G R}\right) \cdot m_{E G R}+m_{E G R} \cdot m_{s c}} \\
& =\frac{m_{f, b} \cdot\left(\frac{A F R_{s t}+1}{A F R_{s t}}\right) \cdot\left(m_{a}+m_{f}+m_{E G R}-m_{s c} \cdot T_{E G R}\right)}{\left(m_{a}+m_{f}\right) \cdot\left(m_{a}+m_{f}+m_{E G R}-m_{s c}\right)} \\
& Y_{b}^{E V O}=\frac{m_{f, b} \cdot\left(\frac{A F R_{s t}+1}{A F R_{s t}}\right)}{m_{a}+m_{f}+m_{E G R}-m_{s c}-\left(\frac{m_{a}+m_{f}+m_{E G R}-m_{s c}}{m_{a}+m_{f}+m_{E G R}-m_{s c} \cdot T_{E G R}}\right) \cdot\left(m_{E G R}-m_{s c} \cdot T_{E G R}\right)}
\end{aligned}
$$




\section{Appendix C. DoE configurations}

[Table 4 about here.]

[Table 5 about here.] 
Appendix D. Detailed results of the DoEs

[Table 6 about here.]

[Table 7 about here.] 


\section{References}

1. Heywood JB. Internal combustion engine fundamentals 1988.

2. Galindo J, Luján JM, Serrano JR, Hernández L. Combustion simulation of turbocharger HSDI Diesel engines during transient operation using neural networks. Applied Thermal Engineering 2005; 25: 877-898. DOI: 10.1016/j.applthermaleng.2004.08.004.

3. Galindo J, Bermúdez V, Serrano JR, López JJ. Cycle to Cycle Diesel Combustion Characterisation During Engine Transient Operation. SAE Technical Paper 200101-3262 2001. DOI:10.4271/2001-01-3262.

4. Payri F, Benajes J, Galindo J, Serrano JR. Modelling of turbocharged diesel engines in transient operation. Part 2: Wave action models for calculating the transient operation in a high speed direct injection engine. Proceedings of the Institution of Mechanical Engineers, Part D: Journal of Automobile Engineering 2002; 216: 479-493. DOI:10.1243/09544070260137507.

5. Barba, C, Burkhardt C, Boulouchos K, Bargende M. A Phenomenological Combustion Model for Heat Release Rate Prediction in High-Speed DI Diesel Engines with Common Rail Injection. SAE Technical Paper 2000-012933 2000. DOI:10.4271/2000-01-2933.

6. Lapuerta M. Estudio fenomenológico de la combustión en motores Diesel rápidos de inyección directa. Universidad Politécnica de Valencia 2003; 58: 181-193. DOI:10.4271/2000-01-2933.

7. Giannattasio P, Micheli D. Phenomenological Modelling of IDI Diesel Engines. SAE Technical Paper 971592 1997. DOI:10.4271/971592.

8. Rakopoulos CD, Rakopoulos DC, Giakoumis EG, Kyritsis DC. Validation and sensitivity analysis of a two zone Diesel engine model for combustion and emissions prediction. Energy Conversion and Management 2004 45: 1471-1495. DOI:10.1016/j.enconman.2003.09.012.

9. Payri F, Margot X, Gil A, Martín J. Computational Study of Heat Transfer to the Walls of a DI Diesel Engine. SAE Technical Paper 2005-01-0210 2005. DOI: 10.4271/2005-01-0210.

10. Gil Megías A, Benajes Calvo J, Margot X. Caracterización del flujo de aire en el cilindro de motores Diesel DI mediante cálculo tridimensional. Universidad Politécnica de Valencia 2003.
11. Gatowski JA, Balles EN, Chun KM, Nelson FE, Ekchian JA, Heywood JB. Heat Release Analysis of Engine Pressure Data. SAE Technical Paper 841359 1984. DOI: $10.4271 / 841359$.

12. Lapuerta M, Armas O, Hernández JJ. Diagnosis of DI Diesel combustion from in-cylinder pressure signal by estimation of mean thermodynamic properties of the gas. Applied Thermal Engineering 1999; 19: 513-529. DOI:10.1016/S1359-4311(98)00075-1.

13. Kamimoto T, Akiyoshi M, Kosaka H. A Numerical Simulation of Ignition Delay in Diesel Engines. SAE Technical Paper 980501 1998. DOI:10.4271/980501.

14. Arrègle J, López JJ, García JM, Fenollosa, C. Development of a zero-dimensional Diesel combustion model. Part 1: Analysis of the quasi-steady diffusion combustion phase. Applied Thermal Engineering 2003; 23: 1301-1317. DOI:10.1016/S1359-4311(03)00079-6.

15. Arrègle J, López JJ, García JM, Fenollosa, C. Development of a zero-dimensional Diesel combustion model. Part 2: Analysis of the transient initial and final diffusion combustion phases. Applied Thermal Engineering 2003; 23: 1319-1331. DOI:10.1016/ S1359-4311(03)00080-2.

16. Egnell R. Combustion Diagnostics by Means of Multizone Heat Release Analysis and NO Calculation. SAE Technical Paper 981424 1998. DOI:10.4271/ 981424.

17. Li J, Chae JO, Park SB, Paik HJ, Park JK, Jeong YS, Lee SM, Choi YJ. Effect of Intake Composition on Combustion and Emission Characteristics of DI Diesel Engine at High Intake Pressure. SAE Technical Paper 970322 1997. DOI:10.4271/970322.

18. Kwon SI, Arai M, Hiroyasu H. Ignition Delay of a Diesel Spray Injected into a Residual Gas Mixture. SAE Technical Paper 911841 1991. DOI:10.4271/911841.

19. Yi Y, Hessel R, Zhu GS, Reitz RD. The Influence of Physical Input Parameter Uncertainties on Multidimensional Model Predictions of Diesel Engine Performance and Emissions. SAE Technical Paper 200001-1178 2000. DOI:10.4271/2000-01-1178.

20. Brown WL. Methods for Evaluating Requirements and Errors in Cylinder Pressure Measurement. SAE Technical Paper 670008 1968; 76: 50-77. DOI:10.4271/ 670008 . 
21. Lancaster DR, Krieger RB, Lienesch JH. Measurement and Analysis of Engine Pressure Data. SAE Technical Paper 750026 1975. DOI:10.4271/750026.

22. Neo GH, Collings N. Pressure Data Analysis of Formula One Racing Engines. SAE Technical Paper 970061 1997. DOI: $10.4271 / 970061$.

23. Ångström HE. Cylinder Pressure Indicating with Multiple Transducers, Accurate TDC-Evaluating, Zero Levels and Analyse of Mechanical Vibrations; Conference paper. 3rd International Indicating Symposium, Mainz am Rhein 1998.

24. Hohenberg G. Experimentelle Erfassung der Wandwärme von Kolbenmotoren (Experimental acquisition of the wall heat in piston engines) 1980 .

25. Ghojel J, Honnery D. Heat release model for the combustion of diesel oil emulsions in DI diesel engines. Applied Thermal Engineering 2005; 25: 2072-2085. DOI:10.1016/j.applthermaleng.2005.01.016.

26. Fox JW, Cheng WK, Heywood JB. A Model for Predicting Residual Gas Fraction in Spark-Ignition Engines. SAE Technical Paper 931025 1993. DOI: $10.4271 / 931025$.

27. Ivansson $\mathrm{N}$. Estimation of the Residual Gas Fraction in an HCCI-engine using Cylinder Pressure. Undergraduate Thesis, Linkoping University 2003.

28. Tribotte P, Ravet F, Dugue V, Obernesser P, Quechon N, Benajes J, Novella R, De Lima D. Two Strokes Diesel Engine - Promising Solution to Reduce CO2 Emissions. Procedia - Social and Behavioral Sciences 2012; 48: 2295-2314. DOI:10.1016/j.sbspro.2012.06.1202.

29. Benajes J, Novella R, De Lima D, Quechon N, Obernesser P. Implementation of the Early Injection Highly Premixed Combustion Concept in a 2-Stroke HSDI Engine. SIA Diesel Powertrain Congress 2012.

30. Wu Y, Wang Y, Zhen X, Guan S, Wang J. Threedimensional CFD (computational fluid dynamics) analysis of scavenging process in a two-stroke freepiston engine. Energy 2014; 68: 167-173. DOI 10.1016/j.energy.2014.02.107.

31. Yuan C, Feng H, He Y, Xu J. Combustion characteristics analysis of a free-piston engine generator coupling with dynamic and scavenging. Energy 2016; 102: 637-649. DOI:10.1016/j.energy.2016.02.131.
32. Sastry GVJ, Chandra H. A Three-Zone Heat Release Model for DI Diesel Engines. SAE Technical Paper 940671 1994. DOI:10.4271/940671.

33. Timoney DJ. Problems with heat release analysis in DI diesels. SAE Technical Paper 870270 1987; 96: 259268. DOI: $10.4271 / 870270$.

34. Kamimoto T, Minagawa T, Kobori S. A Two-Zone Model Analysis of Heat Release Rate in Diesel Engines. SAE Technical Paper 972959 1997. DOI:10.4271/ 972959.

35. Klein M, Eriksson L. A specific heat ratio model for single-zone heat release models. SAE Technical Paper 2004-01-1464 2004. DOI:10.4271/2004-01-1464.

36. Cheung HM, Heywood JB. Evaluation of a OneZone Burn-Rate Analysis Procedure Using Production SI Engine Pressure Data. SAE Technical Paper 932749 1993. DOI:10.4271/932749.

37. Brunt MFJ, Rai H, Emtage AL. The Calculation of Heat Release Energy from Engine Cylinder Pressure Data. SAE Technical Paper 981052 1998. DOI:10.4271/ 981052 .

38. Eriksson L. Requirements for and a Systematic Method for Identifying Heat-Release Model Parameters. SAE Technical Paper 980626 2003; 1998. DOI:10.4271/ 980626.

39. Payri F, Molina S, Martín J, Armas O. Influence of Measurement Errors and Estimated Parameters on Combustion Diagnosis. Applied Thermal Engineering 2006; 26: 226-236. DOI:10.1016/j.applthermaleng. 2005.05.006.

40. Armas Vergel O, Payri González F,. Diagnóstico experimental del proceso de combustión en motores Diesel de inyección directa. Universidad Politécnica de Valencia 1999.

41. Broatch A, Ruiz S, Margot X, Gil A. Methodology to estimate the threshold in-cylinder temperature for self-ignition of fuel during cold start of Diesel engines. Energy 2010; 35: 2251-2260. DOI:10.1016/j.energy. 2010.02.012.

42. Olsen D, Hutcherson G, Wilson B, Mitchell C. Development of the Tracer Gas Method for Large Bore Natural Gas Engines: Part 1 - Method Validation. Journal of Engineering for Gas Turbines and Power 2002; 124: 678-685. DOI:10.1115/1.1454116. 
43. Olsen D, Hutcherson G, Wilson B, Mitchell C. Development of the Tracer Gas Method for Large Bore Natural Gas Engines: Part 2 - Measurement of Scavenging Parameters. Journal of Engineering for Gas Turbines and Power 2002; 124: 686-694. DOI: 10.1115/1.1454117.

44. Galliot F, Cheng WK, Cheng CO, Sztenderowicz M, Heywood JB, Collings N. In-Cylinder Measurements of Residual Gas Concentration in a Spark Ignition Engine. SAE Technical Paper 900485 1990. DOI:10.4271/ 900485

45. Cho H, Lee K, Lee J, Yoo J, Min K. Measurements and Modeling of Residual Gas Fraction in SI Engines. SAE Technical Paper 2001-01-1910 2001. DOI:10.4271/ 2001-01-1910.

46. Sinnamon JF, Sellnau MC. A New Technique for Residual Gas Estimation and Modeling in Engines. SAE Technical Paper 2008-01-0093 2008. DOI:10.4271/ 2008-01-0093.

47. Benajes J, Olmeda P, Martín J, Carreño R. A New Methodology for Uncertainties Characterization in Combustion Diagnosis and Thermodynamic Modelling. Applied Thermal Engineering 2014; 71: 389-399. DOI: 10.1016/j.applthermaleng.2014.07.010.

48. Payri F, Olmeda P, Martín J, García A. A Complete OD Thermodynamic Predictive Model for Direct Injection Diesel Engines. Applied Energy 2011; 88: 4632-4641. DOI:10.1016/j.apenergy.2011.06.005.

49. Payri F, Galindo J, Martín J, Arnau FJ. A Simple Model for Predicting the Trapped Mass in a DI Diesel Engine. SAE Technical Paper 2007-01-0494 2007. DOI: 10.4271/2007-01-0494.

50. Benajes J, Novella R, De Lima D, Tribotte $P$, Quechon N, Obernesser P, Dugue V. Analysis of the Combustion Process, Pollutant Emissions and Efficiency of an Innovative 2-Stroke HSDI Engine Designed for Automotive Applications. Applied Thermal Engineering 2013; 58: 181-193. DOI:10.1016/j.applthermaleng. 2013.03.050.

51. Benajes J, Martín J, Novella R, Thein K. Understanding the performance of the multiple injection gasoline partially premixed combustion concept implemented in a 2-Stroke high speed direct injection compression ignition engine. Applied Energy 2016; 161: 465-475. DOI:10.1016/j.apenergy.2015.10.034.
52. Benajes J, Novella R, De Lima D, Thein K. Impact of injection settings operating with the gasoline Partially Premixed Combustion concept in a 2-stroke HSDI compression ignition engine. Applied Energy 2017; 193: 515-530. DOI:10.1016/j.apenergy.2017.02.044.

53. Galindo J, Serrano JR, Arnau FJ, Piqueras P. Description and Analysis of a One-Dimensional Gas-Dynamic Model With Independent Time Discretization. Journal of Engineering for Gas Turbines and Power 2008; 1313: 034504-034504-5. DOI:10.1115/ICES2008-1610.

54. Galindo J, Serrano JR, Arnau FJ, Piqueras P. Description of a Semi-Independent Time Discretization Methodology for a One-Dimensional Gas Dynamics Model. Journal of Engineering for Gas Turbines and Power 2009; 187-197. DOI:10.1115/1.2983015.

55. Arrègle J, and López JJ, Martín J, Mocholí, EM. Development of a Mixing and Combustion ZeroDimensional Model for Diesel Engines. SAE Technical Paper 2006-01-1382 2006. DOI:10.4271/ 2006-01-1382.

56. Carreño Arango, R. A comprehensive methodology to analyse the Global Energy Balance in Reciprocating Internal Combustion Engines. Thesis, Universitat Politècnica de València 2016. DOI:10.4995/Thesis/ $10251 / 73069$.

57. Benajes J, Olmeda P, Martín J, Blanco-Cavero D, Warey A. Evaluation of swirl effect on the Global Energy Balance of a HSDI Diesel engine. Energy 2017; 122: 168-181. DOI:10.1016/j.energy.2017.01.082.

58. Payri F, López JJ, Martín J, Carreño R. Improvement and application of a methodology to perform the Global Energy Balance in internal combustion engines. Part 1: Global Energy Balance tool development and calibration. Energy 2018; 152: 666-681. DOI:10.1016/ j.energy.2018.03.118. 


\section{List of Figures}

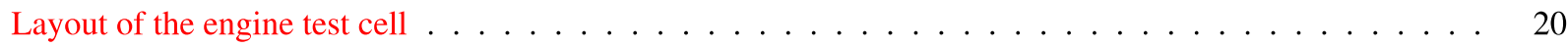

2 Scavenge and Trapping Ratio of the engine (CFD results) . . . . . . . . . . . . . . . . . 21

3 Cylinder pressure (left) and Exhaust and Intake pressures (right) correlations between engine measurements

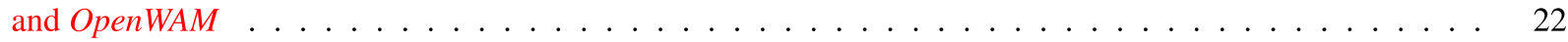

4 Comparison between different estimator approaches . . . . . . . . . . . . . . . . 23

5 Comparison between the IGR estimators for DoE 1 (left) and DoE 2 (right) . . . . . . . . . . . . . . . 24

6 Sensibility of the different versions of the estimator for DoE 1 (4 left plots) and DoE 2 (4 right plots) . . . . 25

7 Comparison between the Heat Release at two operating points, considering the residual mass estimated by the two models . . . . . . . . . . . . . . . . . . . . . . . . . . 26

8 Comparison between the in-cylinder temperature and heat transfer at two operating points, considering the residual mass estimated by the two models . . . . . . . . . . . . . . . . . . . . . . . . . . . 27 


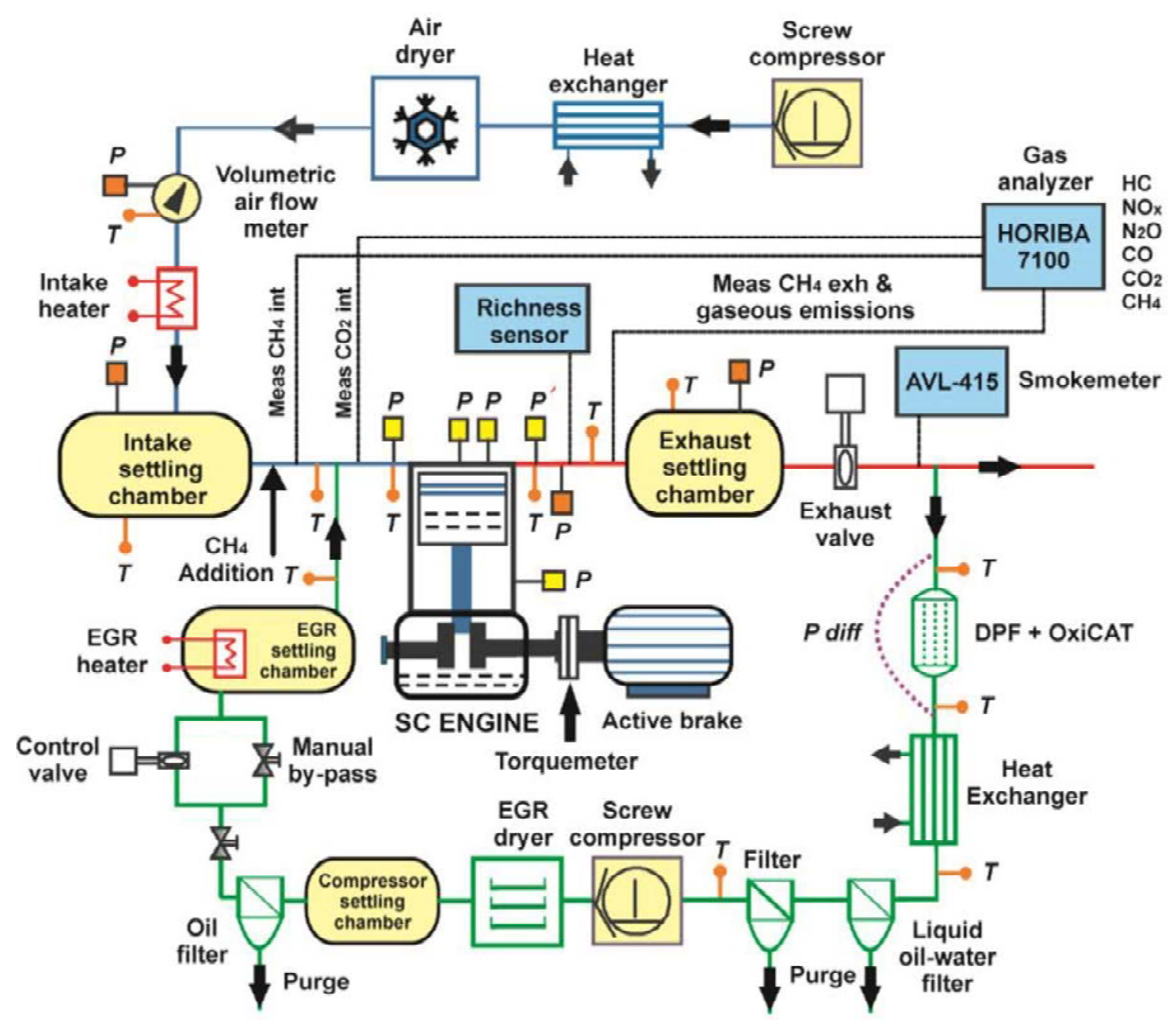

Figure 1. Layout of the engine test cell 
Swept of burnt gases

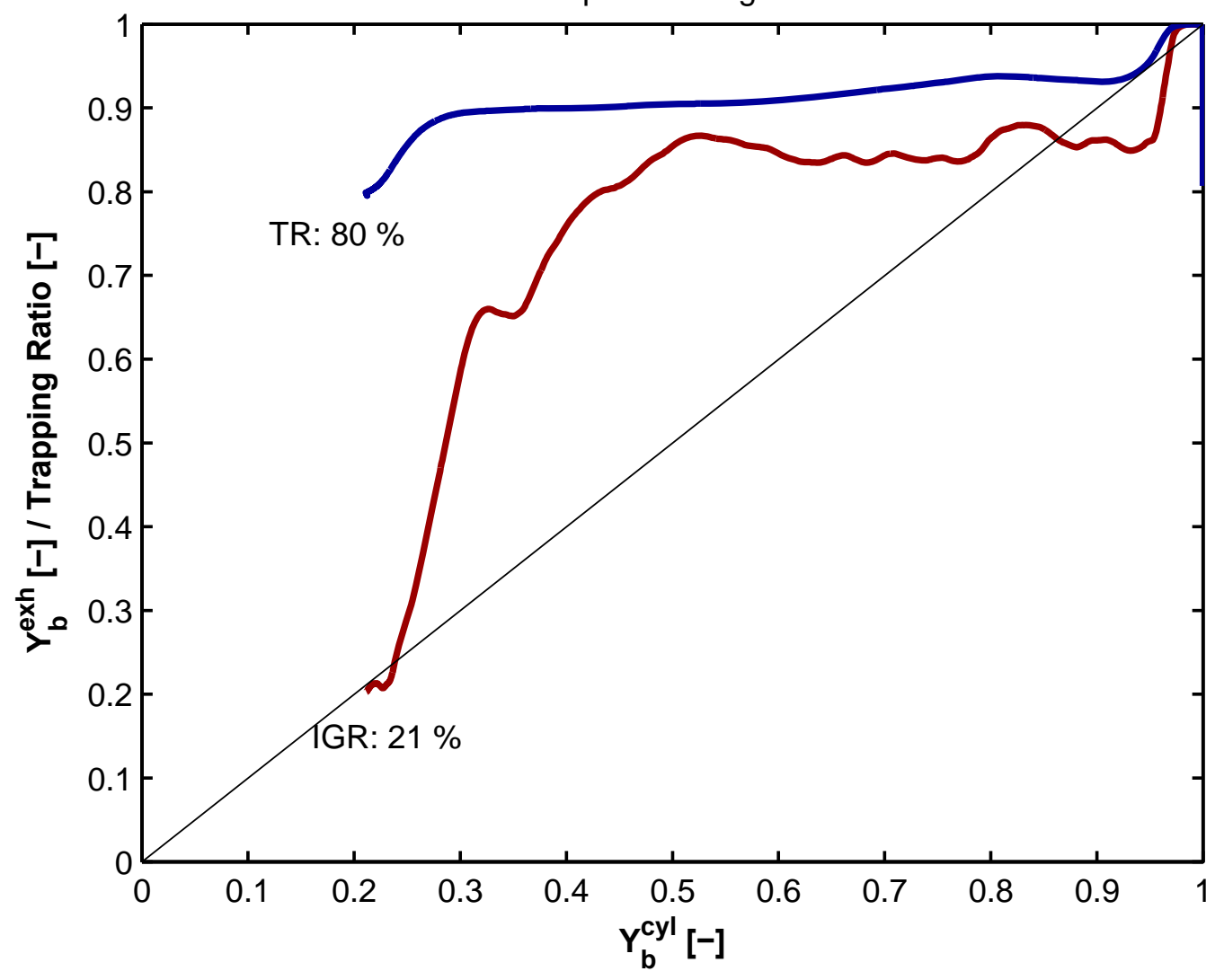

Figure 2. Scavenge and Trapping Ratio of the engine (CFD results) 

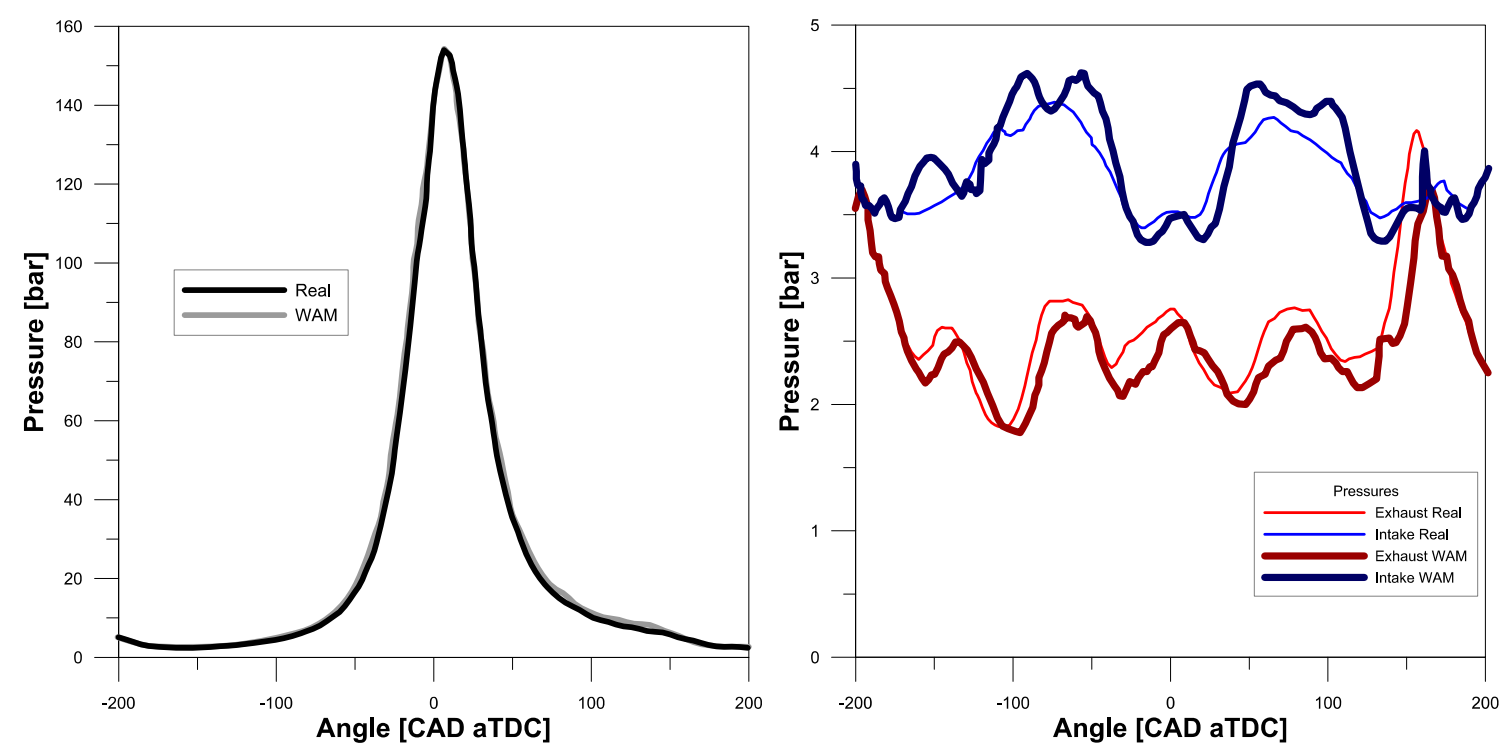

Figure 3. Cylinder pressure (left) and Exhaust and Intake pressures (right) correlations between engine measurements and OpenWAM 


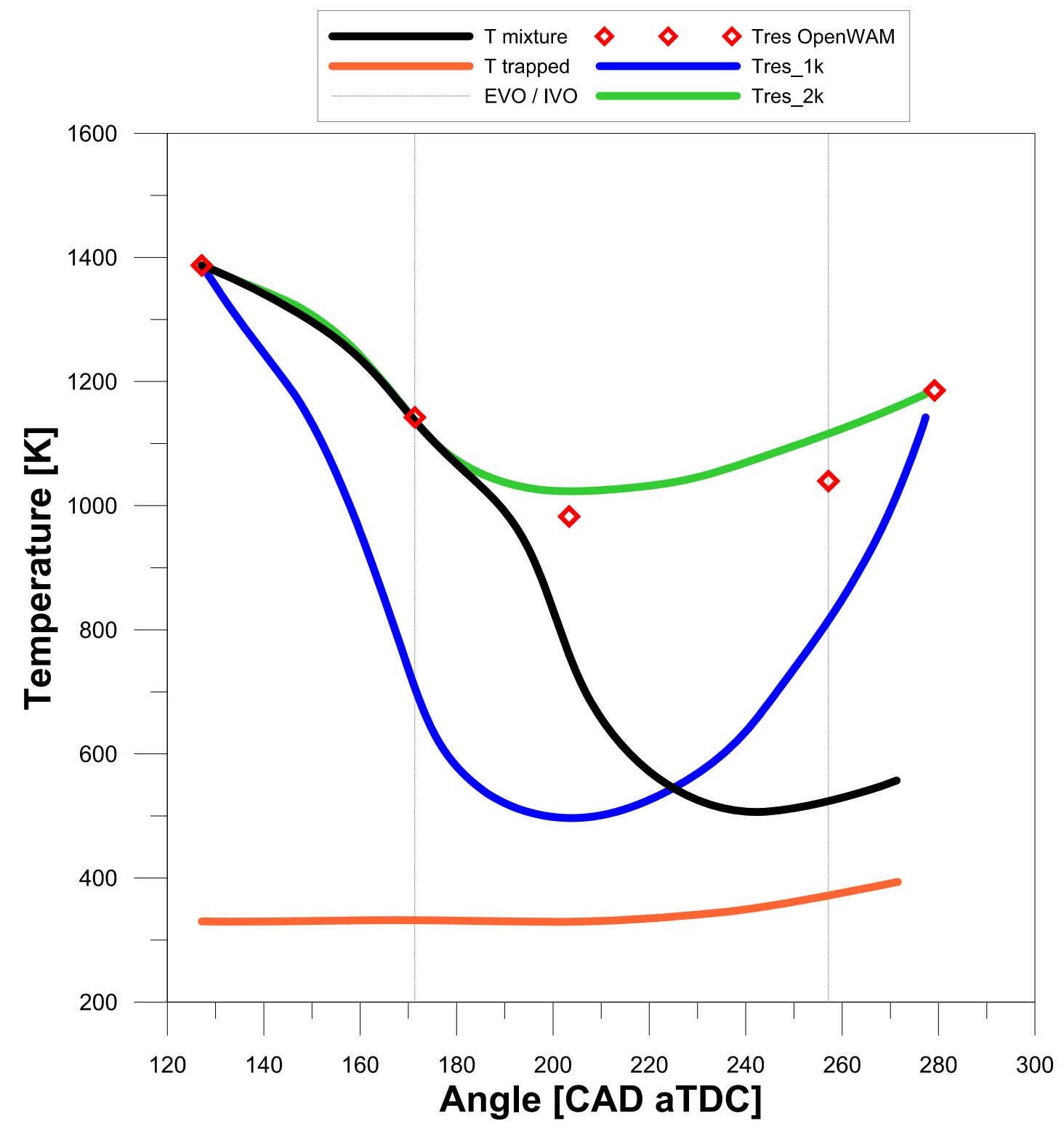

Figure 4. Comparison between different estimator approaches 


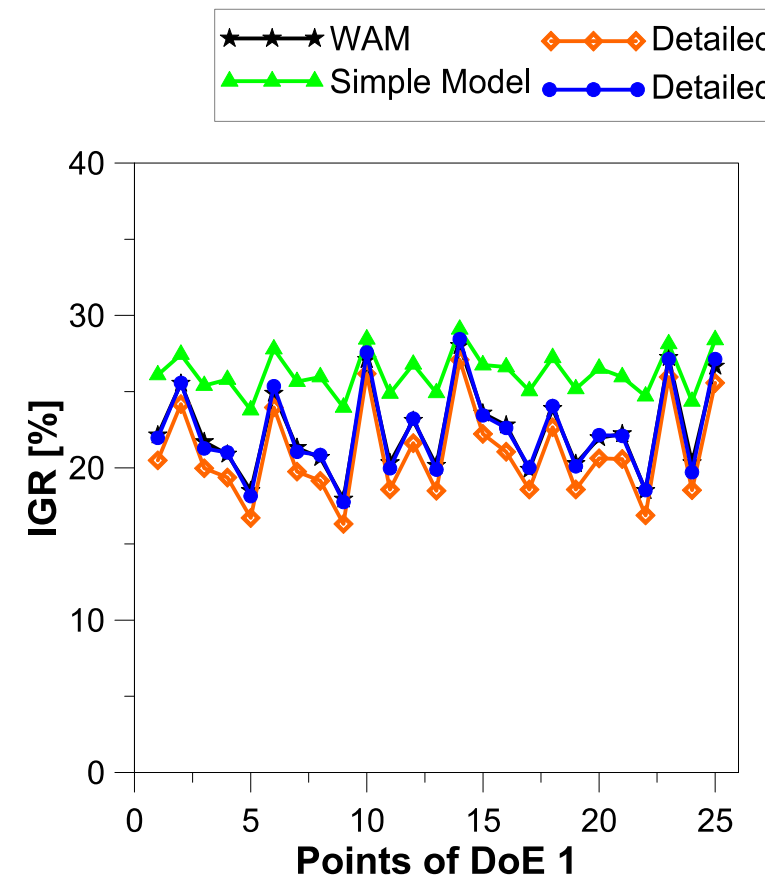

$$
\begin{aligned}
& \text { Model }\left(k_{\text {int }}=1.35 ; k_{\text {exh } 1}=1.40 ; k_{\text {exh2 }}=1.20\right) \\
& \text { Model }\left(k_{\text {int }}=1.30 ; k_{\text {exh } 1}=1.40 ; k_{\text {exh2 }}=1.20\right)
\end{aligned}
$$

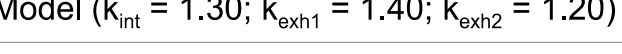

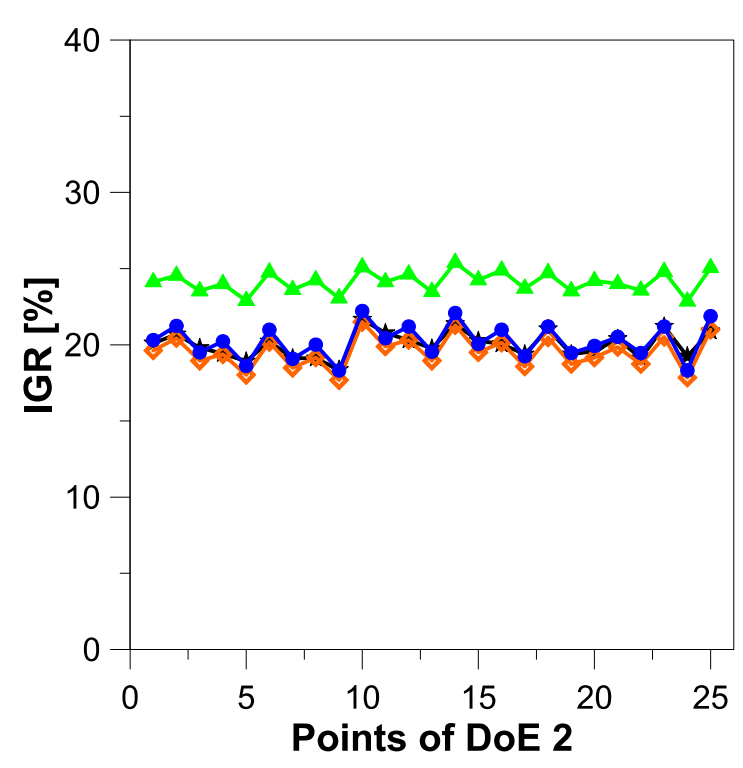

Figure 5. Comparison between the IGR estimators for DoE 1 (left) and DoE 2 (right) 

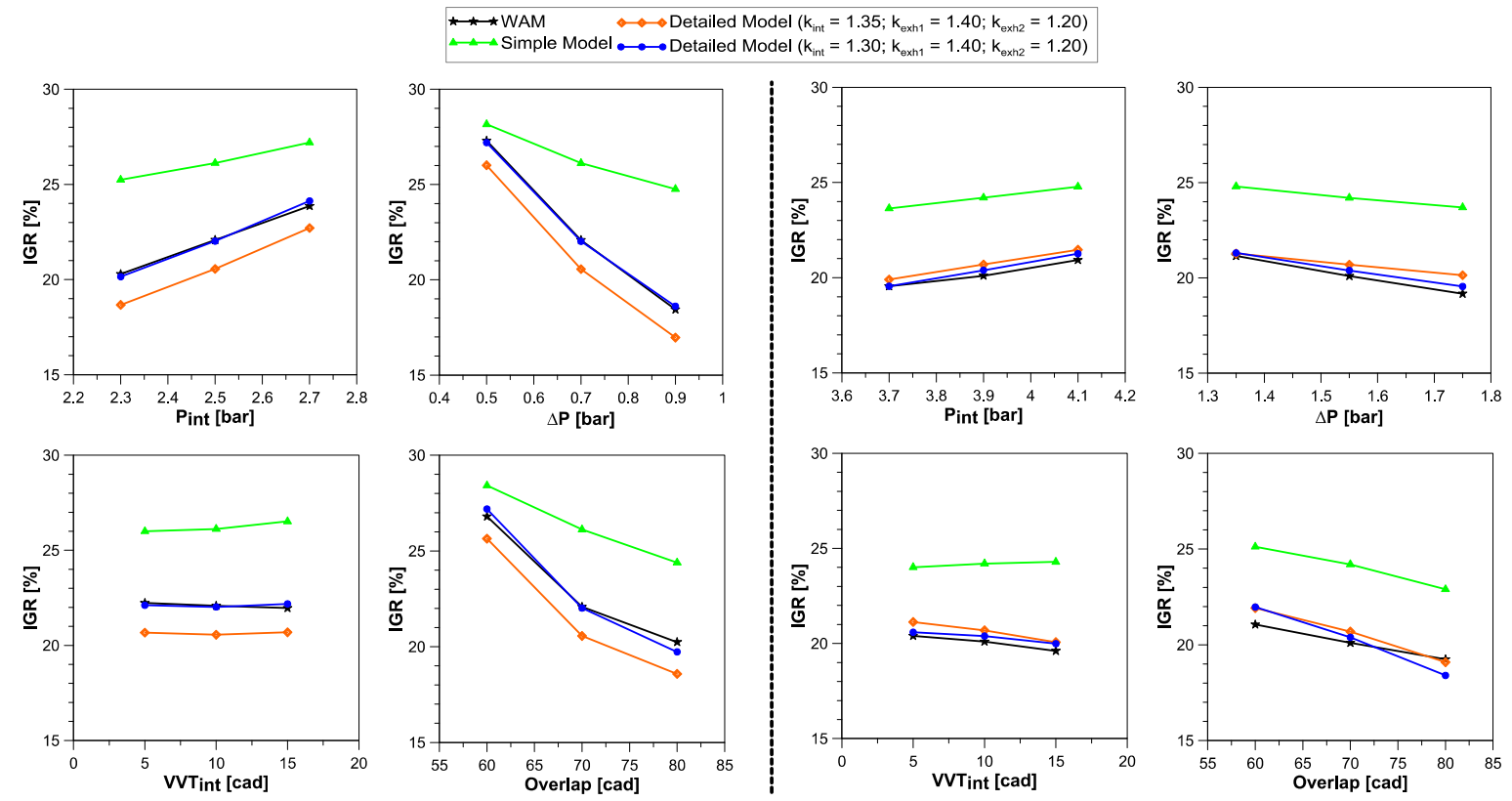

Figure 6. Sensibility of the different versions of the estimator for DoE 1 (4 left plots) and DoE 2 (4 right plots) 

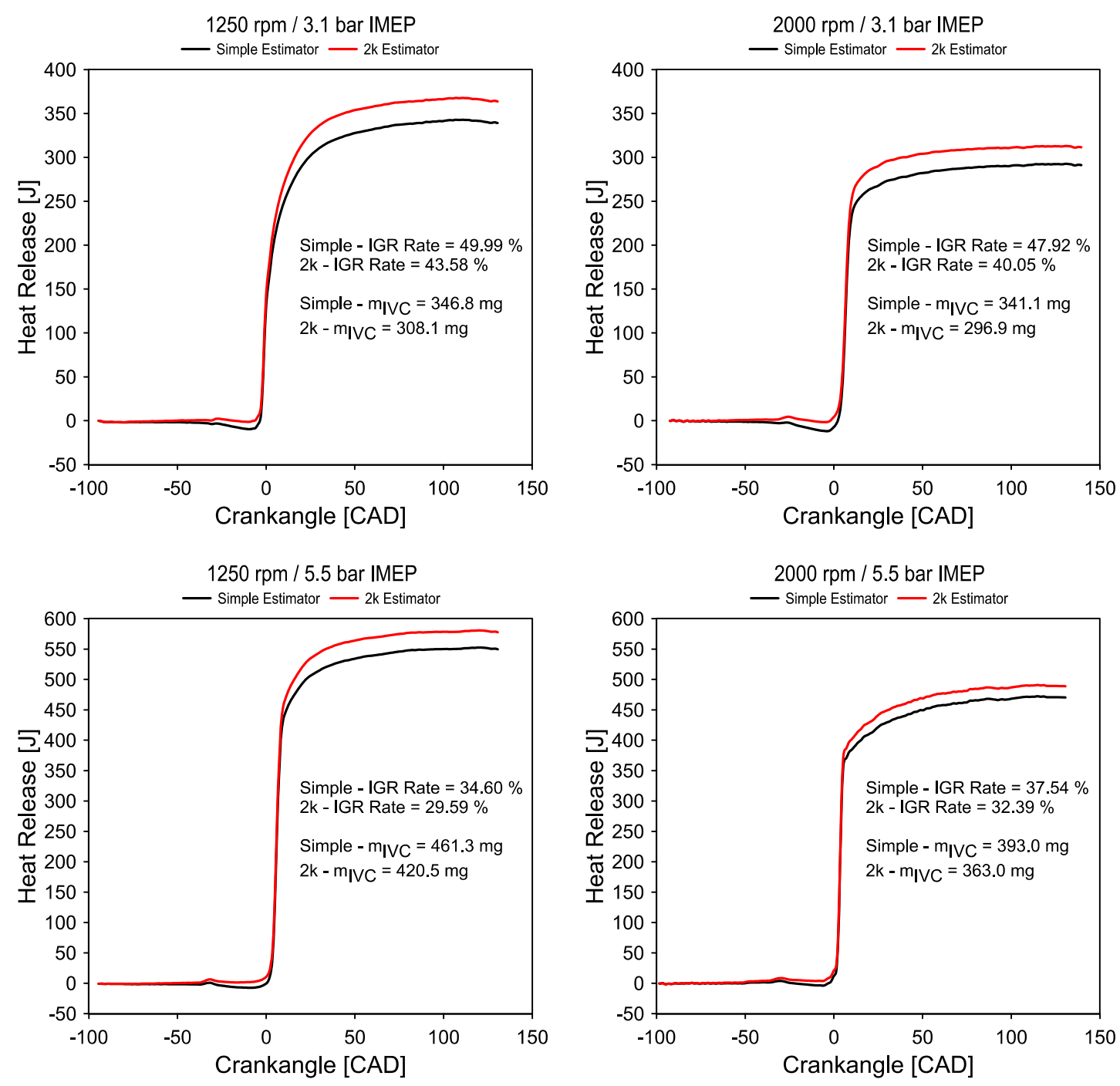

Figure 7. Comparison between the Heat Release at two operating points, considering the residual mass estimated by the two models 

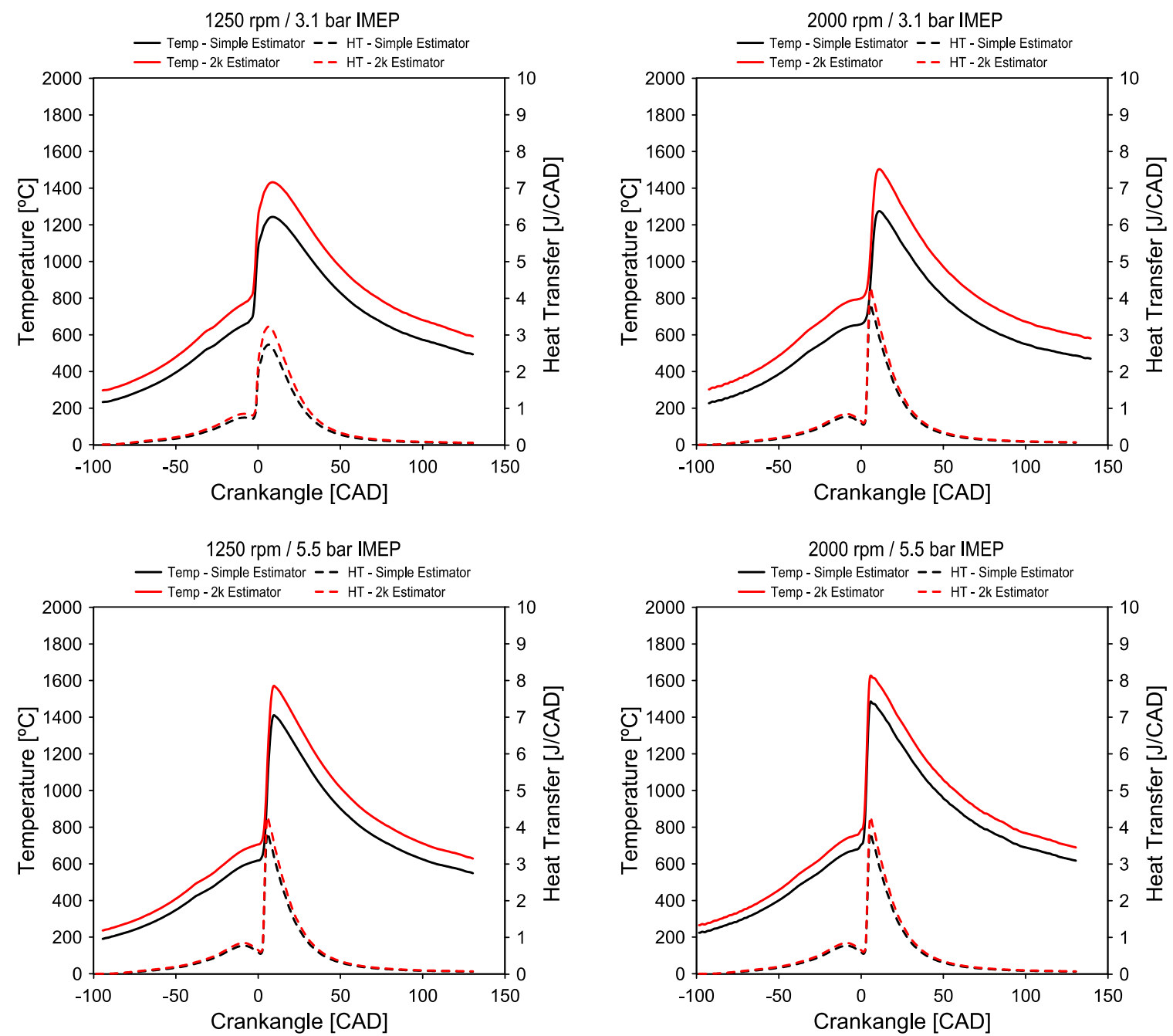

Figure 8. Comparison between the in-cylinder temperature and heat transfer at two operating points, considering the residual mass estimated by the two models 


\section{List of Tables}

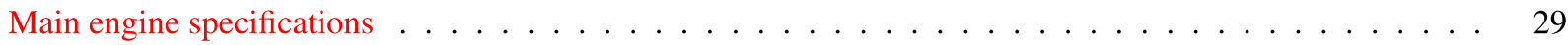

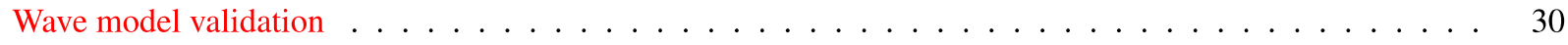

DoEs reference points . . . . . . . . . . . . . . . . . . . . . 31

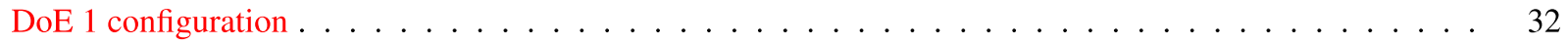

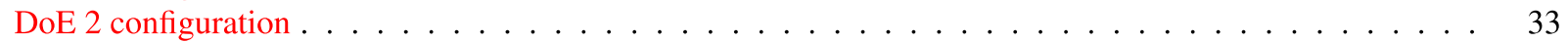

Results of DoE 1 - IGR rates . . . . . . . . . . . . . . . . . . . . . . . . . 34

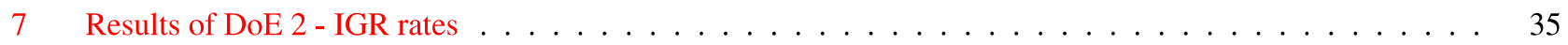


Table 1. Main engine specifications

\begin{tabular}{|c|c|}
\hline Engine Type & 2-stroke compression ignition \\
\hline Displacement (Bore x Stroke) & $365 \mathrm{~cm}^{3}(76 \times 80.5 \mathrm{~mm}$, single cylinder $)$ \\
\hline Connecting Rod Length & $133.75 \mathrm{~mm}$ \\
\hline Compression Ratio & $17.6: 1$ \\
\hline Fuel injection system & Diesel common rail HSDI \\
\hline Injector nozzle & 10 holes, $80 \mu \mathrm{m}, 148^{\circ}$ spray included angle \\
\hline Number of Valves & 4 ( 2 intake $/ 2$ exhaust $)$ \\
\hline Type of scavenge & Poppet valves with scavenge loop \\
\hline Valvetrain & DOHC with VVA \\
\hline $\begin{array}{l}\text { Nominal intake valve timing } \\
\left(\text { set at } \mathrm{VVT}_{\text {int }}=\mathbf{0}\right)\end{array}$ & $\begin{array}{l}\text { IVO }=161.9 \mathrm{CAD} \text { aTDC } \\
\mathrm{IVC}=251.6 \mathrm{CAD} \text { aTDC }\end{array}$ \\
\hline $\begin{array}{l}\text { Nominal exhaust valve timing } \\
\text { (set at } V_{V} T_{e x h}=0 \text { ) }\end{array}$ & $\begin{array}{l}\mathrm{EVO}=122.6 \mathrm{CAD} \text { aTDC } \\
\mathrm{EVC}=226.9 \mathrm{CAD} \text { aTDC }\end{array}$ \\
\hline
\end{tabular}


Table 2. Wave model validation

\begin{tabular}{l|ccc} 
& OpenWAM & Experimental & \%Error \\
\hline \hline Admitted mass $(\mathrm{kg} / \mathrm{h})$ & 120.01 & 117.89 & $1.77 \%$ \\
Retained mass $(g)$ & 0.61455 & 0.61528 & $0.12 \%$ \\
IGR rate $(-)$ & $21.21 \%$ & $30.26 \%$ & $42.64 \%$ \\
Mass at IVC $(\mathrm{g})$ & 0.78002 & 0.88225 & $13.11 \%$ \\
Trapping Ratio $(-)$ & $76.81 \%$ & $78.29 \%$ & $1.92 \%$ \\
T intake $(K)$ & 307.5 & 309.6 & $0.69 \%$ \\
T exhaust $(K)$ & 807.8 & 797.0 & $1.33 \%$
\end{tabular}


Table 3. DoEs reference points

\begin{tabular}{|c|c|c|}
\hline & $\begin{array}{c}\text { Point } 1 \\
\text { (medium load / low speed) }\end{array}$ & $\begin{array}{c}\text { Point } 2 \\
\text { (high load / high speed) }\end{array}$ \\
\hline Speed (rpm) & 1500 & 2500 \\
\hline IMEP (bar) & 10.5 & 15.0 \\
\hline Torque (N.m) & 50.2 & 76.4 \\
\hline $\operatorname{Power}(k W)$ & 7.9 & 20.0 \\
\hline $\mathbf{P}_{\text {int }}$ (bar) & 2.50 & 3.90 \\
\hline $\mathbf{P}_{\text {exh }}$ (bar) & 1.80 & 2.55 \\
\hline$\Delta \mathbf{P}($ bar $)$ & 0.70 & 1.35 \\
\hline $\mathbf{V V T}_{\text {int }}(\mathrm{cad})$ & 256.7 & 246.7 \\
\hline $\mathbf{V V T}_{\text {exh }}(\mathrm{cad})$ & 237.4 & 231.4 \\
\hline Overlap $(c a d)$ & 70 & 74 \\
\hline Trapping Ratio (\%) & 70.3 & 78.3 \\
\hline IGR Ratio (\%) & 30.2 & 30.3 \\
\hline In-Cyl Richness (-) & 0.54 & 0.64 \\
\hline
\end{tabular}


Table 4. DoE 1 configuration

\begin{tabular}{c|ccc|ccc|} 
& $\begin{array}{c}\boldsymbol{P}_{\text {int }} \\
\text { [bar] }\end{array}$ & $\begin{array}{c}\boldsymbol{P}_{\boldsymbol{e x h}} \\
\text { [bar] }\end{array}$ & $\begin{array}{c}\boldsymbol{\Delta} \boldsymbol{P} \\
\text { [bar] }\end{array}$ & $\begin{array}{c}\boldsymbol{V} \boldsymbol{V}_{\text {int }} \\
{[\text { cad] }}\end{array}$ & $\begin{array}{c}\boldsymbol{V} \boldsymbol{V}_{\boldsymbol{e x h}} \\
\text { [cad] }\end{array}$ & $\begin{array}{c}\text { Olap } \\
\text { [cad] }\end{array}$ \\
\hline \hline 1 & 2.5 & 1.8 & 0.7 & 10 & 15 & 70 \\
2 & 2.4 & 1.8 & 0.6 & 7.5 & 7.5 & 65 \\
3 & 2.4 & 1.8 & 0.6 & 7.5 & 17.5 & 75 \\
4 & 2.4 & 1.6 & 0.8 & 7.5 & 7.5 & 65 \\
5 & 2.4 & 1.6 & 0.8 & 7.5 & 17.5 & 75 \\
6 & 2.4 & 1.8 & 0.6 & 12.5 & 12.5 & 65 \\
7 & 2.4 & 1.8 & 0.6 & 12.5 & 22.5 & 75 \\
8 & 2.4 & 1.6 & 0.8 & 12.5 & 12.5 & 65 \\
9 & 2.4 & 1.6 & 0.8 & 12.5 & 22.5 & 75 \\
10 & 2.6 & 2.0 & 0.6 & 7.5 & 7.5 & 65 \\
11 & 2.6 & 2.0 & 0.6 & 7.5 & 17.5 & 75 \\
12 & 2.6 & 1.8 & 0.8 & 7.5 & 7.5 & 65 \\
13 & 2.6 & 1.8 & 0.8 & 7.5 & 17.5 & 75 \\
14 & 2.6 & 2.0 & 0.6 & 12.5 & 12.5 & 65 \\
15 & 2.6 & 2.0 & 0.6 & 12.5 & 22.5 & 75 \\
16 & 2.6 & 1.8 & 0.8 & 12.5 & 12.5 & 65 \\
17 & 2.6 & 1.8 & 0.8 & 12.5 & 22.5 & 75 \\
18 & 2.7 & 2.0 & 0.7 & 10 & 15 & 70 \\
19 & 2.3 & 1.6 & 0.7 & 10 & 15 & 70 \\
20 & 2.5 & 1.8 & 0.7 & 15 & 20 & 70 \\
21 & 2.5 & 1.8 & 0.7 & 5 & 10 & 70 \\
22 & 2.5 & 1.6 & 0.9 & 10 & 15 & 70 \\
23 & 2.5 & 2.0 & 0.5 & 10 & 15 & 70 \\
24 & 2.5 & 1.8 & 0.7 & 10 & 25 & 80 \\
25 & 2.5 & 1.8 & 0.7 & 10 & 5 & 60
\end{tabular}


Table 5. DoE 2 configuration

\begin{tabular}{c|ccc|ccc|} 
& $\begin{array}{c}\boldsymbol{P}_{\text {int }} \\
\text { [bar] }\end{array}$ & $\begin{array}{c}\boldsymbol{P}_{\boldsymbol{e x h}} \\
\text { [bar] }\end{array}$ & $\begin{array}{c}\boldsymbol{\Delta} \boldsymbol{P} \\
\text { [bar] }\end{array}$ & $\begin{array}{c}\boldsymbol{V} \boldsymbol{V}_{\text {int }} \\
\text { [cad] }\end{array}$ & $\begin{array}{c}\boldsymbol{V} \boldsymbol{V}_{\boldsymbol{e x h}} \\
\text { [cad] }\end{array}$ & $\begin{array}{c}\text { Olap } \\
\text { [cad] }\end{array}$ \\
\hline \hline 1 & 3.9 & 2.350 & 1.55 & 10 & 15 & 70 \\
2 & 3.8 & 2.350 & 1.45 & 7.5 & 7.5 & 65 \\
3 & 3.8 & 2.350 & 1.45 & 7.5 & 17.5 & 75 \\
4 & 3.8 & 2.150 & 1.65 & 7.5 & 7.5 & 65 \\
5 & 3.8 & 2.150 & 1.65 & 7.5 & 17.5 & 75 \\
6 & 3.8 & 2.350 & 1.45 & 12.5 & 12.5 & 65 \\
7 & 3.8 & 2.350 & 1.45 & 12.5 & 22.5 & 75 \\
8 & 3.8 & 2.150 & 1.65 & 12.5 & 12.5 & 65 \\
9 & 3.8 & 2.150 & 1.65 & 12.5 & 22.5 & 75 \\
10 & 4 & 2.550 & 1.45 & 7.5 & 7.5 & 65 \\
11 & 4 & 2.550 & 1.45 & 7.5 & 17.5 & 75 \\
12 & 4 & 2.350 & 1.65 & 7.5 & 7.5 & 65 \\
13 & 4 & 2.350 & 1.65 & 7.5 & 17.5 & 75 \\
14 & 4 & 2.550 & 1.45 & 12.5 & 12.5 & 65 \\
15 & 4 & 2.550 & 1.45 & 12.5 & 22.5 & 75 \\
16 & 4 & 2.350 & 1.65 & 12.5 & 12.5 & 65 \\
17 & 4 & 2.350 & 1.65 & 12.5 & 22.5 & 75 \\
18 & 4.1 & 2.550 & 1.55 & 10 & 15 & 70 \\
19 & 3.7 & 2.150 & 1.55 & 10 & 15 & 70 \\
20 & 3.9 & 2.350 & 1.55 & 15 & 20 & 70 \\
21 & 3.9 & 2.350 & 1.55 & 5 & 10 & 70 \\
22 & 3.9 & 2.150 & 1.75 & 10 & 15 & 70 \\
23 & 3.9 & 2.550 & 1.35 & 10 & 15 & 70 \\
24 & 3.9 & 2.350 & 1.55 & 10 & 25 & 80 \\
25 & 3.9 & 2.350 & 1.55 & 10 & 5 & 60
\end{tabular}


Table 6. Results of DoE 1 - IGR rates

\begin{tabular}{|c|c|c|c|c|c|c|c|}
\hline & WAM & Simple Est. & Diff. & $\begin{array}{c}\text { 2k Est. } \\
k_{i n t}=1.35\end{array}$ & Diff. & $\begin{array}{c}\text { 2k Est. } \\
k_{i n t}=1.30\end{array}$ & Diff. \\
\hline 1 & $22.08 \%$ & $26.12 \%$ & 4.04 & $20.56 \%$ & -1.52 & $22.02 \%$ & -0.06 \\
\hline 2 & $25.50 \%$ & $27.44 \%$ & 1.94 & $24.22 \%$ & -1.28 & $25.62 \%$ & 0.12 \\
\hline 3 & $21.72 \%$ & $25.46 \%$ & 3.74 & $20.05 \%$ & -1.67 & $21.32 \%$ & -0.40 \\
\hline 4 & $20.93 \%$ & $25.82 \%$ & 4.89 & $19.44 \%$ & -1.49 & $21.07 \%$ & 0.14 \\
\hline 5 & $18.39 \%$ & $23.86 \%$ & 5.47 & $16.78 \%$ & -1.61 & $18.15 \%$ & -0.24 \\
\hline 6 & $24.91 \%$ & $27.95 \%$ & 3.04 & $23.99 \%$ & -0.92 & $25.41 \%$ & 0.50 \\
\hline 7 & $21.29 \%$ & $25.66 \%$ & 4.37 & $19.81 \%$ & -1.48 & $21.10 \%$ & -0.19 \\
\hline 8 & $20.66 \%$ & $25.96 \%$ & 5.30 & $19.24 \%$ & -1.42 & $20.91 \%$ & 0.25 \\
\hline 9 & $17.96 \%$ & $23.93 \%$ & 5.97 & $16.41 \%$ & -1.55 & $17.83 \%$ & -0.13 \\
\hline 10 & $27.20 \%$ & $28.48 \%$ & 1.28 & $26.26 \%$ & -0.94 & $27.63 \%$ & 0.43 \\
\hline 11 & $20.27 \%$ & $24.95 \%$ & 4.68 & $18.64 \%$ & -1.63 & $19.99 \%$ & -0.28 \\
\hline 12 & $23.13 \%$ & $26.85 \%$ & 3.72 & $21.67 \%$ & -1.46 & $23.28 \%$ & 0.15 \\
\hline 13 & $20.11 \%$ & $24.94 \%$ & 4.83 & $18.57 \%$ & -1.54 & $19.93 \%$ & -0.18 \\
\hline 14 & $28.10 \%$ & $29.06 \%$ & 0.96 & $27.18 \%$ & -0.92 & $28.50 \%$ & 0.40 \\
\hline 15 & $23.59 \%$ & $26.78 \%$ & 3.19 & $22.28 \%$ & -1.31 & $23.51 \%$ & -0.08 \\
\hline 16 & $22.81 \%$ & $26.67 \%$ & 3.86 & $21.13 \%$ & -1.68 & $22.64 \%$ & -0.17 \\
\hline 17 & $19.96 \%$ & $25.14 \%$ & 5.18 & $18.63 \%$ & -1.33 & $20.02 \%$ & 0.06 \\
\hline 18 & $23.86 \%$ & $27.20 \%$ & 3.34 & $22.71 \%$ & -1.15 & $24.13 \%$ & 0.27 \\
\hline 19 & $20.29 \%$ & $25.24 \%$ & 4.95 & $18.67 \%$ & -1.62 & $20.15 \%$ & -0.14 \\
\hline 20 & $21.96 \%$ & $26.52 \%$ & 4.56 & $20.69 \%$ & -1.27 & $22.18 \%$ & 0.22 \\
\hline 21 & $22.23 \%$ & $26.00 \%$ & 3.77 & $20.67 \%$ & -1.56 & $22.11 \%$ & -0.12 \\
\hline 22 & $18.44 \%$ & $24.76 \%$ & 6.32 & $16.97 \%$ & -1.47 & $18.61 \%$ & 0.17 \\
\hline 23 & $27.30 \%$ & $28.16 \%$ & 0.86 & $26.01 \%$ & -1.29 & $27.20 \%$ & -0.10 \\
\hline 24 & $20.24 \%$ & $24.39 \%$ & 4.15 & $18.58 \%$ & -1.66 & $19.73 \%$ & -0.51 \\
\hline 25 & $26.80 \%$ & $28.42 \%$ & 1.62 & $25.64 \%$ & -1.16 & $27.19 \%$ & 0.39 \\
\hline
\end{tabular}


Table 7. Results of DoE 2 - IGR rates

\begin{tabular}{|c|c|c|c|c|c|c|c|}
\hline & WAM & Simple Est. & Diff. & $\begin{array}{c}2 \mathrm{k} \text { Est. } \\
k_{i n t}=1.35\end{array}$ & Diff. & $\begin{array}{c}\text { 2k Est. } \\
k_{i n t}=1.30\end{array}$ & Diff. \\
\hline 1 & $20.10 \%$ & $24.20 \%$ & 4.10 & $20.69 \%$ & 0.58 & $20.39 \%$ & 0.29 \\
\hline 2 & $20.77 \%$ & $24.59 \%$ & 3.82 & $21.40 \%$ & 0.63 & $21.29 \%$ & 0.52 \\
\hline 3 & $19.94 \%$ & $23.60 \%$ & 3.65 & $20.05 \%$ & 0.10 & $19.59 \%$ & -0.36 \\
\hline 4 & $19.63 \%$ & $24.06 \%$ & 4.44 & $20.76 \%$ & 1.13 & $20.28 \%$ & 0.65 \\
\hline 5 & $18.95 \%$ & $22.97 \%$ & 4.03 & $19.45 \%$ & 0.50 & $18.70 \%$ & -0.24 \\
\hline 6 & $20.42 \%$ & $24.85 \%$ & 4.42 & $20.92 \%$ & 0.50 & $21.08 \%$ & 0.65 \\
\hline 7 & $19.37 \%$ & $23.75 \%$ & 4.38 & $19.42 \%$ & 0.05 & $19.17 \%$ & -0.20 \\
\hline 8 & $19.31 \%$ & $24.31 \%$ & 5.00 & $20.32 \%$ & 1.00 & $20.10 \%$ & 0.79 \\
\hline 9 & $18.51 \%$ & $23.15 \%$ & 4.65 & $18.93 \%$ & 0.42 & $18.41 \%$ & -0.10 \\
\hline 10 & $21.73 \%$ & $25.20 \%$ & 3.48 & $22.28 \%$ & 0.55 & $22.30 \%$ & 0.57 \\
\hline 11 & $20.86 \%$ & $24.20 \%$ & 3.34 & $20.90 \%$ & 0.04 & $20.53 \%$ & -0.33 \\
\hline 12 & $20.56 \%$ & $24.65 \%$ & 4.09 & $21.62 \%$ & 1.06 & $21.25 \%$ & 0.70 \\
\hline 13 & $19.80 \%$ & $23.59 \%$ & 3.79 & $20.28 \%$ & 0.48 & $19.60 \%$ & -0.20 \\
\hline 14 & $21.46 \%$ & $25.49 \%$ & 4.03 & $21.86 \%$ & 0.40 & $22.15 \%$ & 0.69 \\
\hline 15 & $20.34 \%$ & $24.35 \%$ & 4.01 & $20.31 \%$ & -0.03 & $20.15 \%$ & -0.20 \\
\hline 16 & $20.22 \%$ & $24.90 \%$ & 4.69 & $21.16 \%$ & 0.95 & $21.06 \%$ & 0.85 \\
\hline 17 & $19.36 \%$ & $23.75 \%$ & 4.39 & $19.74 \%$ & 0.38 & $19.29 \%$ & -0.07 \\
\hline 18 & $20.93 \%$ & $24.78 \%$ & 3.85 & $21.47 \%$ & 0.54 & $21.26 \%$ & 0.34 \\
\hline 19 & $19.55 \%$ & $23.64 \%$ & 4.09 & $19.90 \%$ & 0.35 & $19.55 \%$ & 0.01 \\
\hline 20 & $19.61 \%$ & $24.29 \%$ & 4.67 & $20.07 \%$ & 0.46 & $19.99 \%$ & 0.38 \\
\hline 21 & $20.40 \%$ & $24.01 \%$ & 3.61 & $21.13 \%$ & 0.73 & $20.59 \%$ & 0.19 \\
\hline 22 & $19.17 \%$ & $23.70 \%$ & 4.53 & $20.14 \%$ & 0.97 & $19.55 \%$ & 0.38 \\
\hline 23 & $21.15 \%$ & $24.80 \%$ & 3.65 & $21.28 \%$ & 0.13 & $21.31 \%$ & 0.16 \\
\hline 24 & $19.24 \%$ & $22.90 \%$ & 3.66 & $19.09 \%$ & -0.15 & $18.40 \%$ & -0.84 \\
\hline 25 & $21.06 \%$ & $25.12 \%$ & 4.06 & $21.92 \%$ & 0.86 & $21.97 \%$ & 0.91 \\
\hline
\end{tabular}

